\title{
I. Die Urkunden des Bisthums Warzburg.
}

Aus dem Nachlass des Univ.-Prof. und Archivkonservators Dr. Contzen.

(Fortsetzung.)

\section{Stift Neumunster.}

Gleich dem vorausgehenden Stift Haug vom Bischof Heinrich I. um das J. 1000 auf der Stelle der ersten Hauptkirche gegründet, bestand das Stift bis zur Saekularisation 1803.

An Originalurkunden sind noch 1746 vorhanden, davon 2 aus dem eilften, 52 aus dem zwölften, 90 aus dem dreizehnten, 617 aus dem vierzehnten und 436 aus dem fünfzehnten Jahrhundert, die übrigen 549 aus den folgenden Zeiten bis 1801.

Neumünster hat das älteste Copialbuch des Hochstifts (No. 92); es ist um 1230 geschrieben, in Hochquart, hat 122 Pergamentblätter, jede Seite in zwei Columnen zu je 20 Zeilen, feste deutliche Schrift; der alte Einband von $\mathrm{Holz}$, an dem noch die kleine Kette befestight ist, trägt auf dem Rücken die Aufschrift: Liber censualis. Es beginnt mit einigen Kaiserurkunden und führt dann bis zur Seite 227 die Schenkungen bis zum Jahre 1230 herab; dann folgt die forma celerarii unter dem Dekan Albertus, der urkundlich um diese Zeit vorkommt, und von S. 235 die im April 1233 vorgenommene Aufzeichnung des Ornates und der Bücher des Stiftes (abgedruckt im XVI. Bande Heft 2 S. 245 des Archivs des histor. Vereins zu Würzburg), der eine spätere Verzeichnung aus dem Jahre 1319 beigeschrieben ist; den Schluss machen Einträge von Zinsen nach den Jahresfesten von S. 240-245.

Dieses Copialbuch genügte hundert Jahre; dann empfand man das Bedürfniss einer andern Aufzeichnung. Im Jahre 1334 unter dem Probste Ernst von Seebach wurden nach Capitelsbeschluss die Canoniker Rudiger von Bechelingen, Heinrich Lutwin von Heilbronn und der Vikar Johann von Hall, alle Stiftsgeistliche von Neumünster, 
beauftragt, ein neues Copialbuch zu verfassen, wozu der Canonikus Heinrich von Lynach die Kosten beischoss. Dieser Liber registralis, wie er genannt ist, - sive Registrum omnium et singulorum privilegiorum, instrumentorum, formarum, statutorum et contractuum Ecclesiae Novi Monasterii Herbipolensis - ist nach Rubriken eingetheilt. zerfällt nach dem Inhalt der Urkunden in drei Bücher und jedes Buch wieder in Abtheilungen, ein starker Band von 203 Pergamentblättern, fest und deutlich geschrieben, die Ueberschriften und das Vorwort roth, die Anfangsbuchstaben jeder Urkunde, wie die erste Seite arabeskenartig verziert, jede Seite zu zwei Columnen mit je 40 Zeilen. Der eingetragenen Urkunden bis zum J. 1333 sind 381; in den folgenden Jahren wurden einzelne Nachträge hinzugefügt; die Abschriften sind correkt. Das Buch steht in grossem Ansehen, hatte in judiciis et extra fidem plenam probandi und fülırte von der grossen am ledernen Einbande befestigten Kette den Namen: das grosse Kettenbuch (liber catenatus No. 93).

Diese beiden Bücher, liber censualis und liber registralis, bildeten nun mehrere Jahrhunderte das Mittel, die Originale selbst zu schonen, bis der Urkundenvorrath wieder so anwuchs, dass ein neues Copialbuch nothwendig ward. Dies wurde in der ersten Hälfte des 18. Jahrhunderts begonnen und bis zur Saekularisation des Stiftes fortgeführt. Es umfasst auf Papier geschrieben zehn Bände (No. 113-122); die ersten fünf enthalten die Urkunden, welche die Ortschaften betreffen, sind deshalb alphabetisch geordnet, so dass der fünfte Band ausschliesslich die Stadt Würzburg angeht; leider fehlt in dieser Reihe der zweite, die Buchstaben $G$ und $H$ begreifende Band, der nie ins Archiv kam; die folgenden Bände mit doppelten Registern versehen umfassen die übrigen Urkunden des Stifts, die jüngste ist rom J. 1802. Dieses genau und deutlich geschriebene Copialbuch gewinnt dadurch an Werth, dass es bei jeder Copie am Rande den Lagerort des Originals angibt oder sich auf die beiden alten Copeibücher bezieht.

An diese schliesse ich die für die Verfassung des Stifts so wichtigen Statu tenbü cher, deren sich zwei vorfinden. Das ältere (No. 131) beginnt mit einem Privilegium Bischofs Heinrich vom J. 1163 und führt die einzelnen sich folgenden Urkunden bis 1642 auf, um welche Zeit es geschrieben ist, ein starker Foliant. Das zweite (No. 132) gibt die Verfassung des Stiftes, wie sie 1724 bestand. Die hier verzeichneten Fide der Mitglieder des Stifts 
finden sich zusammengeschrieben in dem Juramentenbuch (No. 134) aus derselben Zeit.

Bei dem Mangel eines Nekrologiums gewinnen der Catalogus D. D. Canonicorum (No. 135), welcher von 1672 bis 1802 lie Namen der als Canoniker Aufgenommenen, ihre Geburts- und 'Todesjahre und ihre stiftischen Würden auf's genaueste angibt, ein Papierband in $4^{0}$, sodann die Tes tam e n tbü cher (No. 123, 124), erhöhte Bedeutung. Das älteste Testament ist das des Geschichtsschreibers Michael vom Löwen (No. 123, S. 421-26) vom J. 1347, welcher als Canoniker von Neumünster neun Chorstühle und zwei Altäre, und vor einem derselben seine Begräbnissstätte, und für seinen am 3. Juli 1345 verstorbenen Bruder, den Rechtsgelehrten Conrad von Mainz, und für sich Jahrtage in derselben Kirche stiftet (cfr. Regest. Boic. VIII, 136); das jüngste ist aus dem J. 1792.

Die erste Würde bekleidete der Stiftsprobst, welcher nur aus der Zahl der Domherren genommen werden durfte. Das rom Unterprobst bekleidete Probstei-Amt hatte die Aufsicht auf die nicht unbedeutenden Einkünfte des Stiftes und führte die dafür bestimmten Bücher. Das älteste, das sich erhalten hat, ist vom Jahr 1428 in drei Abschriften (No. 94, 95 und 135'): Registrum Praepositurae jurium, censuum, redituum Eccl. S. Joannis Novi Monast. Herbip. collectum per Magistrum Conradum Wellein canonicum et vicepraepositum eccl. antedicte sub A. D. 1428 dominica proxima post Petri cathedra. Alle drei sind Papierhandschriften; vor No. 94 findet sich am Deckel des Einbandes ein Blatt eines Nekrologs, der vielleicht dem Stift Neumünster einst angehörte.

Erneuerungen des Registrums fanden Statt in den Jahren 1468 durch die Unterpröbste Joh. Anger (No. 97), 1496 durch Friedrich Fischer (No. 98), 1514 durch Denselben, welcher des abwesenden Probstes Christoph von Schirding Stelle vertrat (No. 99) 1534 durch Ambrosius Breuss (No. 101), und 1567 durch den Unterprobst Johann Dilthey (No. 102). Alle Diese hielten sich genau an den Text des ältesten Registrums. Erst der berühmte Rechtsgelehrte Johann Wilhelm Gantzhorn, Viceprobst und später Dechant von Neumünster, nahm 1588 eine Umarbeitung vor (No. 105) und verbesserte diese im J. 1591. Dieses sogenannte Probstbuch, eine vortreffliche Arbeit in einem starken Folio-Bande, mit den Wappen der Capitularen vom J, 1581 und einem Verzeichniss der Würdenträger des Stiftes, welches Gropp, Script. I, 847 und $\amalg, 639$ 
und Ussermann, Ep. Wirceb. p. 218 abdrucken liessen, genügte bis zur Auflösung des Stiftes. Eine Copie ist No. 104 a und eine gleich schöne No. 104 b. Einer der Nachfolger machte zu seinem Handgebrauche 1777 einen Auszug daraus (No. 105). Im Anfange des 17. Jahrhunderts wurden die Urkunden, auf denen die Probsteirechte ruhten, in einem Bande zusammengeschrieben (No. 107): Probstey: Copeven. Papier, 1192 Seiten mit dem Anfang eines Registers.

Zum Amt des Präsenzmeisters gehörte die Bewahrung der Urkunden, welche die Errichtung, die Rechte und Obliegenheiten der dreissig Vikarien im Stifte betrafen; zusammengeschrieben wurden sie in dem liber vicariarum Novi Monasterii (No. 96, fol. 470 Blatt Pap.) von dem Kirchner Heinrich Behein im J. 1499, und dies Buch ist 1594 durch den Bruderschafts-Prokurator Balthasar Winther erneuert. $\mathrm{Zu}$ seinem Gebrauche diente ferner die Regula censuum et redituum Presentiariae, verfertigt 1570 (No. 103 in zwei Exemplaren). Von dem Kellereiamte sind noch drei Gült- und Zinsbücher (No. 125-127) erhalten. Das Stift hielt viel auf sein Archiv; das sieht man auch aus der Behandlung der noch erhaltenen Repertorien. Das von dem Stifts-Registrator Joh. Balthas. Seebach aus Friedrichsroda in Thüringen 1692 bearbeitete Repertorium ist sehr gut eingerichtet (No. 110 ${ }^{\circ}$ und eine Abschrift davon $110^{\circ}$ ); einen nach Ortschaftery ausgezogenen Index verfasste 1756 der Registrator Joh. Georg Schulz (No. 111). Neben diesen ist ein Repertorium über alle in den Copeibüchern enthaltenen Urkunden, das 1712 verfertigt wurde, sehr brauchbar und übersichtlich eingerichtet, es trägt den Titel: Index generalis über des Collegiatstifts Copei- und Dokumentenbücher (No. 112). Aus diesem Buche ersieht man, dass um 1712 noch zwei Präsenz-Copeibücher aus dem 14. Jahrhundert und vom J. 1500, in denen sich wahrscheinlich das Stiftscalendariun befand, vorhanden waren, die jetzt verloren sind, gleichwie die ältesten Statutenbücher aus den J. 1499 und 1558, desgleichen der erste Band des Catalogus Canonicorum, der von 1113 bis 1672 reichte, und das Lehenprotokollbuch in zwei Bänden. Die Capitels-Protokolle von Neumünster fangen mit dem J. 1553 an und gehen bis 1802, sie umfassen 54 Bände.

Dies reiche Quellenmaterial ist weder für Neumünster noch für das Stift Haug bis jetzt wissenschaftlich verwerthet worden. 
2. Die Ordens-Commenden im Bisthum Würzburg.

\section{A. Doutscher Orden.}

Yon den zwölf Balleien, in welche der Orden während der Zeit seiner Blüthe einst im deutschen Reiche sich verzweigte, galt die Ballei Franken für die bedeutendste. Sie umfasste ausser einzelnen Ordenshäusern 23 Komthureien oder Commenden, die von Kaisern und Königen, von Fürsten und edeln Herrn wie von frommen Wohlthätern des Bürgerstandes mit Güterreichthum überschüttet waren. Hierzu gehörte die später zu höherer Bestimmung gelangte Komthurei zu Mergentheim, deren bedeutender urkundlicher Nachlass, auf welchen ich hier nicht näher eingehen kann, theils, nachdem das schöne Archivgebäude zu Mergentheim seit 1869 zu andern Lwecken verwendet ist, jetzt in Ludwigsburg, theils im k. Staatsarchive zu Stuttgart bewahrt wird. Hier haben wir es nur mit den beiden Commenden zu Würzburg und zu Münnerstadt zu thun, weil nur über diese uns die Quellen zu Gebote stehen. Beide theilten schliesslich das Loos ihres Ordens, der bekanntlich in J. 1809 (24. April) durch Napoleon für aufgelöset erklärt ward; seine Güter wurden nun Staatsgut.

\section{Commende zu Würzburg.}

Gründer derselben war der Bischof Otto von Würzburg, der dem Orden überhaupt behülflich war, in Deutschland festen Fuss zu fassen, und ihm 1219 den sogenannten Königshof, einst Eigenthum Kaiser Friedrich's I., zu seiner Niederlassung schenkte. Hier erbauten die Ritter 1238 Kirche und Ordenshaus, das sie 1695 durch den Baumeister Antonio Petrini neu errichten liessen. Letzteres ist jetzt zu Militärzwecken verwendet, während die schöne in rein deutschem Stile erbaute Kirche leider noch immer verödet steht.

In das $k$. Archiv sind abgegeben worden und haben sich erhalten 146 Urkunden, davon 42 aus dem 13. Jahrhundert, deren älteste die genannte des Bischofs Otto vom J. $1219^{\prime}$ ist, 28 aus dem 14., 11 aus dem 15. und 65 aus der folgenden Zeit bis 1802 .

Ein Copialbuch, im 16. Jahrhundert angefangen und später fortgesetzt, enthält im ersten Bande die Urkunden mehr chronologisch, im zweiten nach Ortschaften geordnet (No. 152 und 153). Ein gedruckter kleiner Band enthält die Privilegien des Ordens (No.151). 
2. Commende zu Münnerstadt.

Die Grafen von Henneberg waren es, die den Orden noch vor der Mitte des 13. Jahrhunderts nach Münnerstadt brachten und reich dotirten. Im folgenden Jahrhundert ward die Comthurei von Schweinfurt mit der hiesigen vereinigt. Nach der Auflösung ward in das Ordenshaus das $k$. Rentamt verlegt. Ueber das Geschichtliche vergl. Reininger, Münnerstadt und seine Umgebung, Würzburg 1852 S. 58 u. ff.

Im Archive zu Würzburg sind 157 Urkunden übrig, 28 aus dem 13. Jahrhundert, die älteste ist von 1251, dann 52 aus dem 14., 44 aus dem 15. und 33 aus der spätern Zeit bis 1745 .

Ein Copialbuch - Documenta inclyti ordinis teutonici commendae Munnerstatt - ist um 1718 geschrieben und jede Urkunde von dem Mergentheimer Archivar Kheull collationirt (No. 155). Sauberer Einband in gepresstem weissen Leder. - Ein Saal-oder Lagerbuch, renovirt im J. 1607 (No. 156), verbreitet sich aufs ausführlichste über die Güter, Zehnten, Zinsen und Gülten, Rechte und Gerechtigkeiten der Comthurei. Ein älteres kleines Zinsbuch (No. 154), um die Mitte des 14. Jahrhunderts angelegt, auf Pergament, ist unvollständig erhalten.

Ueber die Einrichtung und die Schicksale des Ordens in Deutschland siehe das vortreffliche Werk von Joh. Voigt, Geschichte des deutschen Ritter-Ordens in seinen zwölf Balleien in Deutschland, Berlin, $2^{`}$ Bde. 1857-59; besouders I, 31-64.

\section{B. Johanniterorden.}

Im dritten Jahrzent des zwölften Jahrhunderts hatte derselbe schon eine Niederlassung zu Würzburg unter dem Namen S. OswaldsSpital im Sande, welcher in der Mitte des folgenden Jahrhunderts die Benennung S. Johannis-Spital folgte, dem ein Commenthur vorstand. Reichliche Schenkungen ermöglichten um diese Zeit auch die Errichtung einer zweiten Comthurei zu Biebelried, zwei Stunden von Würzbuirg und Kitzingen. Aufgehoben wurde die Commende im Jahre 1803, die Kirche 1813 eingelegt; das Ordenshaus ist jetzt zu einem Privatgebäude umgeschaffen.

Erhalten haben sich 482 Urkunden, sieben aus dem 12., 110 aus dem 13., 156 aus dem 14., 54 aus dem 15. Jahrhundert und 155 aus der folgenden Zeit bis 1801; ferner ein Diplomatarium 
aus dem J. 1504 (No. 140), unter dem Titel: Copey etlicher Briff sagende über Zins Gult Rente Gevelle und Nutzung dem Haus Sannet Johanns Ordenns zu Würtzburg unnd Bibelried zustenndig, auss Bevelle des Erwirdigenn gestrenngenn Herrn Niclausenn Stoltz ron Gaubickelnhenn Comether gemelts Haus abgeshriebenn wordenn, und durch Bruder Johannsenn Wartweynn von Karlstatt also in Ordnung bracht unnd registrirt Auno Domini 1504. fol. 525 Blätter Papier; eine Copey etlicher Verschreibungen von Zinsen und (iütern aus dem J. 1520 (No. 141), Repertorien aus den Jahren 1606, 1715, 1758, 1769 und besonders rom Jahre 1794, dem die Geschichte der Commende vorausgeht, woraus Scharold 1835 seine Darstellung derselben im Bd. DI, Heft 2, S. 144 bis 150 des Archirs des histor. Vereines zum Theil geschöpft hat. (No. 142. 144-48). Ueber die Privilegien des Ordens das gedruckte Werk in fol. Paris 1700 (No. 143); über die Statuten desselben in italienischer Sprache ein Werk in 4. zu Borgonovo 1719 gedruckt, ein zweites geschriebenes (No. 138. 139). Verirrt hat sich hieher ein Manuscript, in 4.: Relation historique sur la prise de Malta pour les Francais sous les ordres du general Bonaparte en. Juin 1798 (No. 149).

3. Die Collegiatstifter ausserhalb der Stadt Würzburg und die Klöster des Bisthums in alphabetischer

Ordnung.

St. Afra in Wurzburg.

Zuerst als Hospital im J. 1097 genannt, wurde es um 1151 ein Frauenkloster Benedictinerordens, in spiritualibus dem Abte von St. Stephan unterworfen, und, früher ausserhalb der Stadt gelegen, wegen der Befestigung derselben im J. 1673 in die Stadt verlegt und 1802 säcularisirt. Die Kirche ist in ein Privathaus, nun das Seninarium puerorum, verwandelt, die Klostergebäude sind jetzt theils Waisenhaus, theils Bierbrauerei.

An Original-Urkunden haben sich nur 43 erhalten, davon zwei aus dem 14. (die älteste 1343), eine aus dem 15. Jahrhundert, die übrigen 40 später bis zum J. 1773. Ein Copialbuch findet sich in dem Urbar- Zins- und Lehen-Buch vom J. 1573 (No. 160^). Das älteste Urbarbuch ist vom J. 1512, worin sich ein Verzeichniss der seit der Reformation des Klosters im J. 1498 gestorbenen Kloster- 
frauen findet (No. 157). Ihre Namen wurden in der Folge in ein Calendarium eingetragen, wovon sich ein Exemplar im k. Archiv (No. 160), ein zweites etwas erweitertes im historischen Vereine (M. S. fol. 183) und ein drittes aber dürftigeres in der Oniversitätsbibliothek befindet. Eine Copie des alten Urbars aus dem J. 1756 enthält No. 158, und eine Sammlung der Recesse aus dem vorigen Jahrhundert No. 159.

Der historische Verein besitzt ausser dem Nekrologium Rechnungen des Klosters aus den J. 1691-92, 1700, 1720-23 (M. S. fol. 278).

Eine Zusammenstellung der Aebtissinnen bei Ussermann pag. 331-34.

\section{Agnetenkloster in Würburg.}

Das Clarissenkloster zu S. Agnes, im J. 1254 seinen Anfang nehmend, auf dem Platze des jetzigen geistlichen Seminars, wurde mit päpstlicher Genehmigung, als seinem ursprünglichen Zwecke entfremdet, 1572 aufgehoben. Die Einkünfte desselben bildeten die orste Grundlage der von Bischof Julius gegründeten und noch jetzt blühenden gelehrten Unterrichtsanstalt in Würzburg.

Die Reihe der wohlerhaltenen Urkunden, meist Kaufbriefe, beginnt mit einer päpstlichen Bulle vom J. 1257, worin Papst Alexander das Kloster von jeder Leistung an die päpstlichen Gesandten und Andere freispricht. Es folgen dann 157 Erwerbsbriefe ununterbrochen von $1277-1379$, von da bis zur Aufhebung sind nur vier Urkunden vorhanden, darunter die des Bischofs Conrad von Thüngen über die Reformation des Klosters im J. 1527. Unter den folgenden findet sich eine fürstliche Weisung an das Archivariat vom 31. August 1773, alle die Gesellschaft Jesu betreffenden Urkunden unmittelbar an das fürstliche Cabinet zu behändigen. Von den 170 Urkunden gehören 35 dem 13., 125 dem 14., zwei dem 15. Jahrhundert, die übrigen acht der folgenden Zeit an.

Sehr wichtig sind die zwei erhaltenen Copialbücher des wohlhabenden Klosters; das eine (A) befindet sich in der Registratur des Verwaltungsausschusses der k. Universität, das zweite (B) im k. Archive (No. 161). Beide sind von derselben Hand geschrieben, welche als die eines Copisten in der fürstlichen Kanzlei unter Bischof Julius häufig begegnet. Die Einträge sind weder in chronologischer noch topographischer Ordnung gemacht, sondern bunt durcheinander, wie die Urkunden dem Schreiber in die Hand kamen. Beide Bände 
grehïren zusammen und bilden die erste und zweite Abtheilung des zur Zeit der Copirung noch vorhandenen Urkunden-Torrathes. Während bis zu diesem Zeitpunkte (etwa 1585) nur noch 164 Originale sich erhalten haben, befinden sich in A: 193, in B: 158, im Ganzen 351 Urkunden, darunter 15 von Würzburger Bischöfen, copirt und mit den Originalen collationirt. Von diesen ist eine (in A pag. 91) angeblich aus dem J. 1007, die aber sicher einer spätern Zeit angehört; aus dem 13. Jahrhundert sind 32 eingetragen, die alle noch im Original vorhanden sind; die drei weitern Originale stammen aus dem landesherrlichen und domcapitelischen Archive. Aus dem 14. Jahrbundert haben wir noch 125 Originale, während sich in A und B: 190 eingetragen finden; aus dem 15. Jahrhundert 2 Originale und 82 in beiden Copialbüchern, aus dem 16. ebenfalls nur 2 Originale und 45 in den letztern copirt. Es sind also von der Zeit des Bischofs Julius bis zur Einrichtung des k. Archivs, also in etwa 220 Jahren. (von 1585-1805), gegen 187 OriginalUrkunden einer einzigen geistlichen Stiftung zu Verlust gegangen, und doch hatten diese Dokumente in dem fürstlichen Archive, in welches sie seit der Aufhebung des Klosters aufgenommen wurden, einen verhältnissmässig viel sicherern Aufbewahrungsort, als dies bei den Urkunden der übrigen den Unbilden der Zeit mehr ausgesetzten einzelnen Stiftern und Klöstern der Fall war.

Eine Prozessschrift von geringer Bedeutung aus dem J. 1612 bewahrt der historische Verein in seinen Sammlungen (M. S. fol. 81).

Eine Bearbeitung der Klostergeschichte gab Ign. Denzinger $1854 \mathrm{im}$ XIII. Bande des Archivs des historischen Vereines von Unterfranken S. 1-100. Hiebei ist blos das Copialbuch A benutzt. Was vorerst Noth thut, hier wie bei Bearbeitung der Geschichte der übrigen Stiftungen, ist die Darlegung des vorhandenen urkundlichen Materials in Regestenform.

\section{Amorbach,}

eine Meile ron Miltenberg am Main, Benedictiner-Abtei, in der ersten Hälfte des 8. Jahrhunderts (angeblich 714) gegründet, im J. 1659 von der Würzburger Diöcese getrennt und mit fast allen seinen Besitzungen der Mainzer einverleibt, 1802 säcularisirt und als Entschädigung dem Fürsten von Leiningen zugetheilt.

Erhalten haben sich kaum 40 Urkunden, die älteste vom J. 1272, grössstentheils an Leiningen extradirt und zu Amorbach aufbewahrt. 
Zur Feier des tausendjährigen Bestehens der Abtei schrieb der gelehrte würzburger Benedictiner von S. Stephan, Ignaz Gropp, eine Geschichte derselben unter dem Titel: Aetas mille annorum monasterii B. M. V. in Amorbach, Francof. 1736. fol., worin er in der Vorrede über seine Quellen berichtet und gegen 90 Urkunden mittheilt.

\section{Anhausen,}

Pauliner Eremitenkloster an der Jagst zwischen Crailsheim und Kirchberg im K. Württemberg, im J. 1357 von Lupold von Bebenburg, Bischof von Bamberg, dessen Ahnherr, Wolfram von Bebenburg, gerade 200 Jahre früher das berühmte Kloster Schönthal gegründet hatte, gestiftet, im Bauernkriege zerstört und 1557 von dem Markgrafen von Ansbach säcularisirt; liegt jetzt in Ruinen.

Im k. Archiv zu Nürnberg befinden sich noch 129 Urkunden dieses Klosters, davon 23 aus dem 14., 80 aus dem 15. und 26 aus dem 16. Jahrbundert; ferner zwei Copialbücher aus neuerer Zeit und eine Beschreibung des Grundbesitzes vom 14.-16. Jahrhundert. Vergl. U s s er m a nn Ep. Wirc. pag. 503 und cod. prob. No. 91, 97 u. 98, wo drei Urkunden abgedruckt sind, und From $\mathrm{m}$, Kloster und Weiler Anhausen, in der Zeitschrift des histor. Vereins für das württemberg. Franken, Heft 3 (1849) S. 40, mit vier Urkunden S. 99. Nicht zu verwechseln mit den zwei Benedictincrklöstern gleichen Namens: das eine im Oberamt Heidenheim, K. Württemberg, 1123 gegründet, wovon noch mehrere Urkunden, Saal- und Lagerbücher im k. Staatsarchiv zu Stuttgart vorhanden sind; das andere, das richtiger $\mathbf{A u}$ hausen genannt wird, an der Wörnitz im Bisthum Eichstädt, wo 1608 die protestantische Union verabredet wurde.

\section{Insbach,}

früher Onolsbach, ein Benedictinerstift, um die Mitte des 8. Jahrhunderts durch den h. Gumbert gegründet, 1057 in ein Collegiatstift verwandelt und 1563 säcularisirt. Im Archiv zu Nürnberg sind noch 1327 Urkunden dieser Stiftung vorhanden, davon 1 aus dem 8., 1 aus dem 10., 10 aus dem 11., 24 aus dem 12., 49 aus dem 13., 283 aus dem 14., 607 aus dem 15. und 352 aus dem 16. Jahrhundert. Ferner sind dort vier Nekrologien und Anniversarienbücher, die unter meinen Nekrologien beschrieben sind, und ein Copialbuch in drei Bänden aus dem vorigen Jahrhundert. 
Im Archiv zu Würzburg befindet sich eine einzige Lirkunde ron 1468. Ueber den Ursprung des Klosters eine reiche Literatur. (fr. Ussermann, p. 246. - Huscher im 9. Jahresbericht des histor. Vereips von Mittelfranken 1839 S. 107-140. - Rettberg, Kirchengeschichte Deutschlands, Göttingen 1848. Bd. II. S. 339.

\section{Astheim,}

Karthause bei Volkach am IIain, von dem Ritter Erkinger von Seinsheim, dem Gründer des fürstlich Schwarzenbergischen Geschlechtes, im J. 1409 unter dem Namen Pons Mariae, Mariä-Brück, gestiftet, im J. 1802 säcularisirt. Die vor einigen Jahren stilgerecht restaurirte Kirche enthält die Gräber der Ahnen der fürstlich Schwarzenberg'schen Familie.

Im Ganzen haben sich nur 16 Originalurkunden erhalten, davon 7 aus dem 15. Jahrhundert, die älteste vom J. 1410 vom Kaiser Ruprecht, wodurch er Astheim Stadtrecht verleiht (abgedruckt bei Lü n i g, Bd. 33 S. 1313), die übrigen aus der folgenden Zeit bis 1751. Dann ist ausser der besonderen Copie des Stiftungsbriefes (abgedruckt bei Ussermann Cod. probat. No. 101, und Schannat Sammlung historischer Schriften S. 91) im k. Archive zu Würzburg ein gutes Copialbuch vorhanden, von Johann Abt des Klosters zu S. Egidien zu Nürnberg im J. 1497 verfertigt und mit einigen Nachträgen später versehen (No. 239).

Im historischen Verein finden sich eine Kloster'chronik von Augustin Fleischmann, Bamberg 1754. (Manuscr. N. f. 32), ein jüngeres Copialbueh (M. S. f. 770), und Aufzeichnungen aus den Jahren 1629, 1741 und 1748 (M. S. f. 372 und f. ${ }^{*} 160$ ).

Der fürstliche Kanzleidirector B u rkhardt zu Schwarzenberg gab eine urkundliche Geschichte der Karthause Astheim (Ostheim) im IX. Bande des Archivs des histor. Vereins, Heft 1, S. 1-80, wozu nur die Regesten vermisst werden.

\section{Augustinerklöster.}

Die Würzburger Diöcese hatte seit der zweiten Hälfte des 13. Jahrhunderts zwei Klöster der Augustiner-Eremiten, die noch jetzt bestehen; das eine in $W \ddot{u r z b u r g}$, das andere in $M \ddot{u} n n$ er. stadt; jenes hat, ndchdem es sein Kloster für das Gymnasium und Schullehrer-Seminar hat abtreten müssen (die Kirche wurde 1824 abgebrochen), seinen Sitz im ehemaligen Dominikanerkloster; dieses 
gibt seit 1685 die Lehrkräfte für das dortige Gymnasium und Knabenseminar.

Die Geschichtsquellen fliessen für beide Anstalten sehr spärlich; für Würzburg sind nur 4 Urkunden vorhanden, die älteste von 1263 . die folgenden 3 aus dem 14. Jahrhundert; für Münnerstadt sind 26 Urkunden übrig, eine von 1282,13 aus dem 14., 7 aus dem 15. Jahrhundert, die andern 5 reichen bis 1705 ; ferner ein, in grünem Pergament gebundenes Lehen- und Erbzins-Register aus dem J. 1718, worin sich zugleich Copien von manchen Stiftungs- und Kaufbriefen befinden (No. 245). Der Verfasser P. Onuphrius Schambach benutzte dazú mehrere ältere verloren gegangene Copeibücher.

Der bistorische Verein besitzt die Visitationsprotokolle des ersten Klosters rom J. 1621 und die Capitelsacten ron 1607-51 (M. S. q. 1).

Zwei andere Klöster desselben Ordens waren in Windsheim, angeblich 1291, und in Königsberg um 1350 gegründet worden. Von beiden sind keine Urkunden im Würzburger Archiv vorhanden; über letzteres im historischen Vereine ein Verzeichniss des Einkommens u. s. w. rom Jahr 1536 (M. S. q. 94).

\section{Aura,}

Benedictiner-Abtei an der Saale, unweit Kissingen, Uraugia $\$$. Laurentii, gegründet 1108 durch Otto den Heiligen, Bischof von Bamberg, aufgelöset um 1570. Der erste Abt war der berühmte Chronist Ekkehardus. Sehenswerth sind die Ruinen des Klosters gegenüber den Ruinen der Burg Trimberg. Vergl. hierüber C. Heff n er in XIII. Bande des Archivs des histor. Vereins 1855. Heft 3. S. 159.

Es sind nur 16 Original-Urkunden übrig, die älteste vom $J$. 1165 über eine Schenkung Otto's von Fuchsstatt, die jüngste von 1582, ein Verkaufsbrief von B. Julius; 2 sind aus dem 12, 4 aus dem 14., 3 aus dem 15. Jahrhundert, die übrigen 7 später.

Eine vorzügliche historische Darstellung der Abtei und ihres ersten Abtes lieferte der Domcapitular Dr. Reininger 1862 im XVI. Bande des Archivs des histor. Vereins unter Benützung des bisher bekannten Quellenmaterials. In einer Anmerkung dazu (S. 21) machte ich schon darauf aufmerksam, dass Pertz und Waitz in den Monum. Germ. histor. dieses Aura an der Saale mit dem gleichfalls unter dem B. Otto gegründeten Kloster Aurach (siehe unter Mönch-Aurach), ungeachtet Ussermann (Ejpisc. wirceburg. p. 416 und 419) schon das Richtige hat, verwechselt haben. Wattenbach hat 
darnach in der zweiten Auflage seiner Geschichtsquellen \$. 372 den Fehler der Erstern verbessert.

\section{Banz,}

Benedictiner-Abtei in herrlicher Gegend unweit Staffelstein am Main, gegründet 1069 durch den Markgrafen Hermann von Vohburg und seine Gemalin Alberada, im J. 1802 aufgehoben, nun schön erhaltenes Besitzthum des Herzogs Max von Bayern.

Erhalten haben sich an Urkunden im k. Archiv zu Bamberg 396, davon eine aus dem 11., 4 aus dem 13., 14 aus dem 14., 95 aus dem 15. Jahrhundert und 282 aus der folgenden Zeit.

Im k. Archiv zu Würzburg sind 15 Urkunden vorhanden, 1 aus dem 13. (1239), 1 aus dem 14. Jadrhundert, die andern aus neverer Zeit, und ein im 16. Jahrh. geschriebenes Copialbuch mit spätern Einträgen, Papierhandschrift, nebst einer Rechnung aus dem J. 1573. (No. 162 u. 163). Die kurzen Origines coenobii banzensis, die Ludewig im 2. Bd. der SS. rer. Episcopatus Bamberg. Sp. $48 \mathrm{ff}$. herausgab, sind von dem Abt Henricus, welcher von 1288 bis zur Niederlegung seiner Würde im Anfange des J. 1296 dem Kloster vorstand.

Zwei vorzügliche Arbeiten haben wir über Banz: Diplomatische Geschichte der Benedictiner-Abtei Banz in Franken von 1050 bis 1251 mit 61 (urkundlichen) Beilagen und vier Kupfertafeln, Nürnberg 1803. 8. Verfasser ist der Klosterarchivar Placidus Sprenger; und von P. Oesterreicher, Geschichte der Herrschaft Banz, zweiter Theil enthaltend (110) Urkunden (von 1010-1317) und die Reihe der Aebte, Bamberg 1833. Der erste Band ist nicht erschienen. Die Geschichte des Klosters von Jaeck ist unbedeutend:

\section{Beguinen.}

Das Quellenmaterial findet sich verzeichnet und verwerthet in der Abhandlung von Rost, Ueber Beguinen, insbesondere in ehemaligen Fürstenthum Würzburg, im Archiv des historischen Vereins von Unterfranken, Band IX, Heft 1. (1846), S. 81-145 mit urkundlichen Beilagen, hier S. 120. Seitdem erschien noch: Reininger, Beitrag zur Geschichte der Wallfahrtskirche und ehemaligen Beguinenclause auf dem Kirchberge bei Volkach. Daselbst Bd. XIX, Heft. 1, S. 199-203. 


\section{Biebelried.}

Siehe Johanniterorden.

\section{Bildhausen,}

Cisterzienser Abtei, zwei Stunden von Münnerstadt und ebensoviel von Neustadt a/S., durch den Pfalzgrafen Hermann von Staleck im J. 1156 gegründet, eine Tochter des Kl. Ebrach und Mutter der Kl. Wechterswinkel, Marienburghausen, Heiligenthal und Frauenroth, wurde am 2. Mai .1803 aufgehoben, nachdem sie 647 Jahre bestanden hatte. Der letzte Abt Nivardus Schlimbach, ein gelehrter und wirthschaftlicher Herr, hatte eine ausgezeichnete Sammlung besonders Würzburger Münzen, welche nach dessen Tode 1812 durch den Grossherzog Ferdinand von den Erben um $6000 \mathrm{fl}$. erkauft mit ihm nach Florenz kam. Wo ist sie jetzt? Die schöne Abteikirche wurde 1826 abgebrochen. Was -von Gebäuden noch übrig ist, befindet sich jetzt zur Hälfte im Besitz der Mennonitenfamilie Muselmann, zur Hälfte in der des Weinhändlers Anschütz.

Für die Geschichte des Klosters ist viel Quellenmaterial vorhanden; die Religiosen haben sich fleissig mit der Vorzeit ihrer Abtei beschäftigt; es ist aber zerstreut, weil der letzte Prälat dasselbe in sein ihm angewiesenes Asyl mitnahm. Der Landrichter Rost zu Münnerstadt führt in seiner gut und gründlich geschriebenen Geschichte der Abtei (im nachdem Bande des Archivs des historischen Vereines von Unterfranken 1850) die Quellen an, und zwar Heft II, S. 219-26. Was er besass, ging nach seinem Tode an den historischen Verein über, so dass hier, beim Ordinariate. in der Universitätsbibliothek und im k. Archiv sich das Material zusammenfindet. Da Letzteres ihm verschlossen blieb, so gebe ich zur Ergänzung seiner Notizen, was sich hier findet.

An Originalurkunden sind nur 237 vorhanden. Es sind das wohl jene, welche vor Ausbruch des markgräflichen Krieges gerettet wurden. Der Fürstbischof Melchior Zobel von Giebelstadt benachrichtigte schon im J. 1546 den Abt, dass der Krieg ausbrechen würde, und ermahnte ihn, alle Privilegien, Freiheitsbriefe und andere Dokumente des Klosters in Sicherheit zu bringen, wobei er sich erbat, alle diese Gegenstände zur Aufbewahrung zu übernehmen und mit demselben Fleisse zu bewahren, wie seine eigenen. Abt Johannes liess hierauf fast alle Originaldokumente und Schriften zusammenpacken und schickte solche in einer schwarzen Kiste ver- 
wahrt nach Würzburg. Der markgräfliche Krieg traf wirklich das Kloster aufs härteste und fübrte fast dessen Auflösung herbei: nach mehr als hundertjährigem Mühen und Ringen kehrte erst der frühere Wohlstand zurück. Aber die Urkundenkiste kan nie mehr nach Bildhausen zurück. Bis auf den heutigen Tag, klagt der Chronist des Klosters im Anfange des achtzehnten Jahrhunderts, weiss man noch nicht, wo sie aufgehoben worden ist. Das Kloster Theres hatte aus derselben Veranlassung sein Archiv nach Würzburg geflüchtet und erbat es sich nach Beendigung des Krieges wieder zurück. Die Fürstbischöfe indess behielten die Originale und schickten dem Kloster die Copien davon.

Von den Bibdhäuser Originalurkunden ist die älteste aus dem 12. Jahrhundert (1161 von Bischof Heinrich, die sich bei Ussermann findet), ferner 1 aus dem 13., 5 aus dem 14., 32 aus dem 16. bis zum J. 1803. Von den Copialbüchern ist das älteste aus dem Ende des 15. Jahrhunderts, dem ein altes Formularbuch zur Seite geht (No. 169 und 170); jünger sind die libri variorum contractuum et privilegiorum (No. 164 und 165), von denen letzteres bis zu Ende des vorigen Jahrhunderts reicht; am ältesten ist ein Lehen- und Zinsbuch: 1442 (No. 178*) und renovirt 1501 (No. 174), darüber eine ausführliche Beschreibung vom J. 1771 (No. 173). 2 Klostergeschichten finden sich aus dem 17. Jahrhundert (No. 166 und 167), von denen die erste auch die Generalkapitel des Ordens enthält. Papiere aus dem dreissigjährigen Kriege (No. 171) sind brauchbarer, als ein Protocollum rerum memorabilium (No. 168), das sich fast blos auf die Güterverhältnisse und Einkünfte der reichen Abtei bezieht.

\section{Billigheim,}

Cisterzienser Nonnenkloster, im Thale der Schefflenz zwei Stunden östlich von Mosbach im Grossherzogthum Baden, schon vor 1238 bestanden als Benedictinerinnen-Kloster und von B. Hernann dem Orden der Cisterzienser zugewiesèn, kam im 15. Jahrhundert zur Mainzer Diöcese und ist, unbekannt wann, aber nach dem J. 1463, wahrscheinlich aber erst in Folge der Reformation erloschen. Die Güter wurden vom Erzbischof von Mainz eingezogen. Es ist davon im Würzburger Archiv keine Urkunde mehr übrig.

Cfr. Ussermann p. 482. - Bauer in der Zeitschrift für das würtembergische Franken 1867. VII, 3, S. 531. 


\section{Birkenfeld,}

Cisterzienser Frauenkloster, an der Aisch, k. Bezirksamts Neustadt an der Aisch in Mittelfranken, gegründet um 1276 durch Friedrich III Burggrafen von Nürnberg, und seiner zweiten .Gemalin Helene von Sachsen, im Bauernkriege mit dem grössten Theil der Documente zerstört und 1544 von dem Markgrafen von Ansbach säcularisirt.

Keine Urkunden sind im Würzburger Archive vorhanden, ausser zwei Verträgen des Bischofs von W. mit dem Markgrafen aus dem 15. Jahrhundert.

Vergl. Ussermann l. c. pag. 426 und G. L Lehnes, Geschichtliche Nachrichten von den Orten und ehemaligen Klöstern Riedfeld, Münchsteinach und Birkenfeld, Neustadt a/A. 1833. Lief. III, S. $191-209$.

\section{Birklingen,}

eine Canonie regulirter Chorherrn unweit des Städtchens Jphofen, gegründet im 15. Jahrhundert, im Bauernkrieg 1525 gänzlich zerstört und im Jahre darauf aufgehoben.

Vorhanden sind noch im k. Archive zu Würzburg 100 Urkunden, davon 68 aus dem 15. Jahrhundert, die älteste von 1446 und 32 aus dem 16., die jüngste von 1539; im k. Archive zı Nürnberg 148 Urkunden, davon 1 aus dem 14., 116 aus dem 15. und 31 aus dem 16. Jahrhundert; dann 8 Gültbüchlein aus dem 16. Jahrhundert.

Im histor. Vereine zu Würzburg befinden sich die KlosterRechnungen aus den J. 1623, 27, 42-47. (M. S. f.* 161).

Eine Geschichte des Klosters fehlt. Vergl. die Notiz in Stumpf, Denkwürdigkeiten (1802) Heft 1. S. 73-86.

\section{Bronnbuch,}

Cisterzienser-Abtei bei Wertheim an der Tauber, gegründet 1157 und aufgehoben 1802, nun Eigenthum des Fürsten von Löwenstein -Wertheim-Rosenberg zu Kleinheubach.

Davon sind im k. Archiv noch 13 Urkunden vorhanden, darunter eine undatirte, dem Ende des 12. Jahrhunderts angehörend; die übrigen nach dem 16. Jahrhundert, die jüngste 1800. - Der histor. Vercin besitzt eine KJosterrechnung vom Jahr 1755-56. (M. S. f. ${ }^{*}$ 150).

Aschbach hat in dem Urkundenbuch seiner Geschichte der Grafen von Wertheim (1843) 50 Urkunden abdrucken lassen und zwar theilweise nach einem Copialbuch des 17. Jahrhunderts; Mone machte die Chronik des Klosters von Heinrich Gäbhardt, dem letzten Abte desselben, bekannt in den Schriften des Badener Alterthums- 
Vereines Bd. 2, 307-386 (Karlsruhe 1849) und gab in seiner Zeitschrift Bd. 2, 291-309 eine Anzahl Regesten von 1170-1230 aus einem in der Löwenstein-Rosenbergischen Domainenkanzlei zu Wertheim befindlichen Copialbuch des Klosters, welches 1384 verfertigt, bis zu diesem Jahr 366 Urkunden enthält, und in Bd. 4, 406-434 vollständige Urkunden mit schätzbaren Erläuterungen von $1231-99$.

\section{Carmelitenklöster}

befanden sich in der Diöcese Würzburg folgende:

1) in der Stadt Würzburg seit dem J. 1212 auf dem alten Fischmarkt, seit 1280 auf der Stelle des jetzigen Polizeigebäudes, aufgehoben 1802 ;

2) auf der Vogelsburg, Mons Dei genannt, bei Volkach in herrlicher Lage, 1282 von den Grafen von Castell gegründet und 1525 am 1. Mai mit allen literarischen und urkundlichen Schätzen von den Bauern zerstört und nicht wieder errichtet;

3) zu Neustadtan der Saale im J. 1352 gegründet und 1802 aufgehoben;

4) zu Schweinfurt im J. 1366 orrichtet, im markgräflichen Kriege 1550 zerstört und durch den westphälischen Frieden 1648 ganz aufgehoben;

5) zu Heilbronn in Schwaben im J. 1448 gestiftet und 1802 aufgehoben;

6. Die im J. 1481 durch den Markgrafen Albrecht projectirte Stiftung eines Carmelitenklosters zu Marienkapell bei Crailsheim in Mittelfranken kam nicht zur Ausführung.

Von diesen sechs Klöstern sind nur noch 148 Urkunden vorhanden; davon 2 aus dem 13., die älteste von 1280, 33 aus den 14., 47 aus dem 15. Jahrhundert, die andern 65 aus der folgenden Zeit bis 1801.

Ausserdem mehrere Copialbücher, die ältesten aus dem Anfange des 16. Jahrhunderts; ein Band enthält die Urkunden von 1380-1511, um letzteres Jahr geschrieben, Perg.; ein zweiter die von 1372-1538, auch um diese Zeit zusammengeschrieben, Perg.; diese wurden in den Jahren 1667-68 erneuert unter dem Titel: Carmeli Herbipolensis Jnventarium authenticum onnium immobilium bonorum, donorum, legatorum, censuum et aliorum similium, conArchivalische Zeitschrlft VII. 
fectum A. D. 1667; ein zweiter Band gibt die Fortsetzung von 1646-87, und ein dritter die Bullae et litterae privilegiorum ar gratiarum, geschr. 1668. Auch der liber . censuum conventus Herbipolensis wurde 1505 unter dem Prior Petrus Schweicker angefangen. (Diese alle stehen zusammen unter No. 247). Eine Ërnenerung des liber censuum ron 1667 und ein Zinsbüchlein v. J. 1685 betreffen das Kloster zu Würzburg (No. 249 und 251), ein liber censuum rom J. 1668 das Kloster zu Schweinfurt (No. 250) und ein Protokoll über das liegende und fahrende Vermögen nebst den Copien der Urkunden, vom J. 1667 das Kloster zu Neustadt (No. 257), von welch' letzterem der historische Verein ausser einen Liber decretalis und einer Rechnung von 1615 auch ein Necrologium (M. S. f. 612 ; f.* 149 u. q. 151) besitzt. Ueber Letzteres vergl. die Nekrologien.

Ein Liber visitationis cumi inventariis vom J. 1607 (No. 260) zăhlt die Gefälle und Fahrnisse des Klosters zu Würzburg auf und gibt zugleich den Katalog der an theologischen Werken nicht schlecht bestellten Klosterbibliothek.

\section{Carthaeuser,}

siehe die, auf der Tabelle bemerkten, einzelnen Klöster.

\section{Coburg.}

Obgleich in der. Diöcese Würzburg gelegen, war das dortige. um das J. 1240 gegründete Franziskanerkloster der Mainzischen Abtei Saalfeld untergeben und wurde 1525 aufgehoben. Vergl. Schultes, Coburg. Landesgesch. S. 83.

\section{Crallsheim.}

Siebe Carmelitenklöster.

Dominicanerkloster zu Würzburg.

Es wurde in der ersten Hälfte des vierzehnten Jahrhunderts gegründet. Die drei ältesten päpstlichen Privilegienbriefe sind aus dem J. 1229, und die Urkunden von 1235 und 1249 beziehen sich auf den Bau und die Einweihung der Kirche. Mit der Säinularisation hörte die Wirksamkeit des Ordens auf; Kloster und Kirche wurden später den Augustinern überlassen.

Von Urkunden sind noch 275 übrig, davon 66 aus dem 13., 50 aus dem 14., 72 aus dem 15. Jahrhundert und die andern 87 aus der folgenden Zeit. 
Ein Copialbuch fehlt. Erhalten hat sich nur ein kurzes Zinsregister aus dem 15. Jahrhundert (No. 262), und im historischen Vereine das Buch der Anniversarien der Wohlthäter des Klosters aus dem Jahre 1618.

\section{Ebrach,}

bedeutendste Cisterzienser-Abtei in Franken, an der mittlern Ebrach im Steigerwalde, gegründet 1126, mit prachtvoller 1200-1285 erbauten Kirche, der Grabstätte der Gemalin Kaiser Konrads III und ihres Sohnes Friedrich von Rotenburg, sowie der Herzen der Bischöfe von Würzburg, die im Iseben vielen Kampf mit ihr hatten. Aufgehoben durch die kurbaierische Regierung im J. 1802 ist die berühmte Hohenstaufen-Stiftung jetzt ein - Zuchthaus für weibliche Sträflinge.

Der nicht geringe Vorrath an Originalurkunden, die sich erhalten haben, ist leider zersplittert in den königlichen Archiven zu Würzburg und zu Bamberg aufbewahrt und zwar in folgender Sonderung nach Jahrhunderten:

\begin{tabular}{|c|c|c|c|}
\hline Jahrhundert & $\begin{array}{c}\text { in } \\
\text { Würzburg }\end{array}$ & $\begin{array}{c}\text { in } \\
\text { Bamberg }\end{array}$ & zusanmen \\
\hline XII & 14 & 12 & 26 \\
XIII & 150 & 101 & 251 \\
XIV & 184 & 142 & 326 \\
XV & 149 & 123 & 272 \\
XVI-XVIII & 195 & $729(7$ s.d.) & 924 \\
\hline Summa & 692 & 1107 & 1799 \\
& & &
\end{tabular}

Auch die Copialbücher sind zwischen den beiden Archiven getheilt; in Bamberg befindet sich das älteste, in Würzburg das vollständigste. Jenes führt den Namen Liber Pitanciarum (über die Bedeutung dieses Wortes siehe die Zusammenstellung in Du Cange, Glossar. ed. Henschel. Tom. V. pag. 246) oder Buch der frommen Stiftungen, ein müssiger Band in gross Folio, in weissem gepressten Leder gebunden, 95 Papier- und 12 Pergamentblätter enthaltend, durch Peter von Kottenheim geschrieben und im J. 1340 begonnen. 
Dieser älteste Eiṇtrag befindet sich auf fol. $1-28$ und ist abge druckt in: Wegele, monumenta eberacensia pag. 69-141. Eine etwas ältere Aufzeichnung eines Theiles des Güterbestandes bewahrt der historische Verein, Pergamentlibell in 12, aus dem J. 1313 , abgedruckt bei Wegele, p. 145-154; ein jüngeres Urbar das Archiv zu Würzburg (M. S. no. 26) aus dem Anfange des 15. Jahrhunderts. A us der folgenden Zeit sind eine grosse Anzahl von Lehen-, Zinns- und Salbüchern im kgl. Archive daselbst vorhanden, welche über das allmählige Anwachsen des Besitzstandes und die Verwaltung desselben genaue Auskunft geben.

Ueber die Behandlung dieser Art Geschichtsquellen vergl. Jos. Zahn, die Freisingischen Sal-, Copial- und Urbarbücher, in Archiv für Kunde österreichischer Geschichtsquellen Bd. XXVII, S. 191 bis 344 .

Wichtiger noch ist die Urkunden-Sammlung, fol 29-103, des genannten liber pitanciarum, die erste der Abtei, aus dem J. 1407, jubente venerabili domino Henrico, undecimo Abbate Ebracensi, conscripta. Die Urkunden sind chrouologisch geordnet, nach den sie betreffenden Aemtern zusammengeschrieben, ebenfalls (bis auf die letzten Blätter) von einer Hand und $z$ war die Literae et privilegia ad officium pietancie pertinencia von Blatt 29-58 darunter auf Blatt 33 eine Relatio, a quibus et quando domus hec fundata sit, - bei Wegele pag. $3-7,-$ von $\mathrm{Bl}$. $59-69$, ad off. prioratus pert., $70-78$ custodis, $79-86$ infirmarii; dann folgen von $86^{\mathrm{b}}-103$ die Privilegia Regum et Imperatorum nebst den Urkunden der Würzburger Bischöfe und Bl. 106 ein index locorum von späterer Hand. Von den 23 Urkunden, die von Bischöfen von Würzburg erlassen sind, hat Wegele 6 abdrucken lassen, S. 52--64; früher waren davon schon 3 veröffentlicht worden.

Dieses Buch genügte lange Zeit. Endlich scheinen die Verluste des Archivs zur Zeit des dreissigjährigen Krieges die Nothwendigkeit der Anlage eines neuen Copialbuches fühlbar gemacht zu haben und unter dem thätigen Abte Alberich Degen (1658-1686) wurde das Werk vollendet. Es führt den Namen Liber Palatii, continens Privilegia summorum Pontificum, Cardinalium et Episcoporum itemque Imperatorum, Regum et aliorum Monasterio B. Mariae Virg: de Ebraco concessa, umfasst in deutlich geschriebenen 3 Bänden, Papier folio, denen ein vierter für die vergessenen und spätern Dokumente sich anreiht, die sämntlichen Urkunden des 
Klosters, vidimirt 1673 durch den kaiserlichen Notar Heinrich Klein ron Bamberg, in topographischer Ordnung. Würzburger Archiv No. 179--182. Wie vollständig dieses vortreffliche Buch ist, erhellt aus der Angabe, dass die Anzahl der Urkunden der würzburger Bischöfe von der Stiftung des Klosters bis 1400, welche in der ersten Sammlung nur 22 betrug, hier ein rundes 100 ausmacht, und doch waren von jenen 22 Dokumenten schon 18 abhanden gekommen, die deswegen hier fehlen. Derselbe Abt liess schon vorher 1662-63 durch den P. Gerard Vendt eine Zusammenstellung jener Originale verfertigen, welche die Freiheiten des Klosters betreffen. Dieser Liber Privilegiorum, Papier fol. 1020 Seiten, im Archive zu Würzburg (No. 8300), hat besonders die Streitigkeiten mit Würzburg im Auge.

Auf diese Bücher stützten sich die Verfasser der Klosterchroniken. Ebrach hat sich von den frühesten Zeiten an durch wissenschaftliches Streben nicht unrühmlich ausgezeichnet. Es orrichtete für seine und seines Ordens Geistliche im 13. Jahrhundert zu Würzburg ein Collegium Studiorum, das Bischof Berthold von Sternberg (gest. 1287) zu einer Universität erweitern wollte. Als diese Anstalt in Folge der bürgerlichen Unruhen bald wieder einging, schickte das Kloster seine jungen Männer auf die Hochschulen nach Wien und Heidelberg. Am letzteren Orte erwarb dasselbe zu diesem Zwecke ein eigenes. Haus für seine Angehörigen (domus S. Jacobi in der Vorstadt vergl. Chr. Henriquez, annatot. Menologii ad diem 25. Febr. fol. 64. col. -2), und hier entspann sich zwischen diesen und ihrem berühmten Landsmann Conrad Celtes von Wipfeld ein freundschaftliches Verhältniss, das diesen bewog, im J. 1507, eine Zeitlang in der Abtei zu verweilen. Aus der Zeit dieses Aufenthaltes stammt das historische Werk, das angeblich in einer. Ebracher Handschrift entdeckt bis in die neueste Zeit als Geschichtsquelle gegolten hat: Ligurini de gestis Friderici I Augusti libri $\mathrm{X}$ carmine heroico conscripti, nuper apud Francones, in Sylva Hercinia, et Druidarum Ebracensi coenobio, a Conrado Celte reperti. Vergl. De vita et scriptis C. Celtis. Opus posthumum Eng. Klupfelii edid. J. C. Ruef et C. Zell. Friburgi 1827. 2 Bde.

Damals lebte hier als Prior Johannes Nibling, in Heidelberg gebildet, welcher eine Chronik in 4 Bänden, deren letzten unvollendeten Andreas Denser bis zum J. 1538 fortsetzte, verfasste und darin des Klosters merkwürdige Begebenheiten zu seiner Zeit verzeichnete. Diese Chronik, die noch am Schlusse des. vorigen 
Jahrhunderts in Ebrach aufbewahrt wurde, ist nicht gleich den übrigen Literalien an die öffentlichen Anstalten in Würzburg und Bamberg abgegeben worden und befindet sich wahrscheinlich noch in Privathänden. Auch ein Calendarium aus jener Zeit, mit den Einträgen der Wohlthäter und ihrer Stiftungen, ist spurlos verschwunden.

Erhalten hat sich die Chronik des Abtes Alberich (im Archive zu Würzburg M. S. 29): Chronicon Monasterii B. Mariae Ebracensis in Franconia in duas divisum partes: quarum prima agit de ipso Monasterio, altera de B. Adamo et eius curae subjectis monasteriis aliisque dominis abbatibus eiusdem successoribus; Auctore $\mathbf{R}^{\mathbf{m o}} \mathbf{D}$ ño. Alberico quondam Priore, nunc Abbate - collectum Anno 1653 et descriptum auno 1660. Ein Quartband von 452 Seiten. Seine Quellen sind ausser den Urkunden die oben genannte Relatio, a quibus etc., die in die erste Zeit der Stiftung hinaufreicht und eine um die Mitte des 15. Jahrhunderts verfasste Chronik, unter dem Titel Funiculus triplex, die sich in der hiesigen Universitätsbibliothek erhalten hat, woraus Ruland schon 1834 und Wegele l. c. den historischen Theil veröffentlicht haben. Das S. 81 des Chronicons mitgetheilte Calendarium hat wenig historischen Werth. Von den Töchterklöstern ist Heilsbronn am ausführlichsten behandelt; es sind hier 228 Inschriften der dortigen Denkmäler mitgetheilt und einige Federzeichnungen dazu, wodurch das bekannte Werk von J. L. Hocker, Hailsbronnischer Antiquitäten-Schať, Onolzbach 1731, fol. vervollständigt werden kann.

Alberichs Nachfolger in Priorat und früherer Iehrer (Albericus quondam meus in novitiatu discipulus et tyro, nunc dignissimus pater, magister et dominus II, 413) Joseph Agricola setzte 1660-61 die Chronik desselben fort und ergänzte sie aus den Schätzen des Klosterarchivs in 4 starken Quart-Bänden, die sich ebenfalls im Archive zu Würzburg (M.S. 23) befinden. Der erste Theil, Auctuariun sive continuatio chronici $\rightarrow$ ex diversis authoribus, archivis, literis et documentis - opera P. Josephi p. t. prioris continuati et aucti a. d. 1660, 750 SS. enthält die Geschichte, die Privilegien, die berïhmten Männer von Ebrach und eine Relatio des Zustandes der Abtei zur Zeit des dreissigjährigen Krieges von dem P. Adam Bertellmann 1650 geschrieben; der 2. auf 954 SS. die einzelnen Aebte, ihr Leben und ihre Schriften, darunter des Abtes Johann Laiterbach (1503-1531) rhytmische Beschreibung seiner Leiden 
zur Zeit des Bauernkieges (S. 241-64) und vicle Briefe derselben, ihre Bauwerke im Kloster und in den einzelnen Ortschaften desselben mit Federzeichnungen; der 3 . Theil behandelt auf $816 \mathrm{SS}$. die Töchterklüster von Ebrach in der Würzburger Diöcese: Himmelspforten, Wechterswinkel, Schönau, Marburghausen, Frauenroda, Heiligenthal, Maidbrunn, S. Johann unter Wildberg, Birkenfeld, Tückelhausen, Birklingen und die Reuerinnen in Würzburg, nach den in diesen Klöstern damals noch vorhandenen Quellen, von denen er unter andern das verlorene Necrologium von Himmelspforten auszugsweise in sein Buch aufnahm (S. 218-249); der 4. Theil enthält ausser andern eine Bibliotheca scriptorum, qui in Ebraco et monasteriis eidem mediate vel immediate subjectis floruerunt, darunter der bescheidene Verfasser mit einer stattlichen Anzahl Büchern fol. 273, und 2 Beschreibungen des Klosters mit hübschen Handzeichnungen. Die vielen Auszüge aus der Chronik des Joh. Nibling machen den Verlust derselben weniger empfindlich.

Zu einer bedeutendern wissenschaftlichen Arbeit brachte es aber erst Eugen Montag, der als letzter Abt die lange Reihe seiner Vorgänger würdig schliesst.

Geboren zu Ebrach am 5. März 1741, zum Abt gewählt am 21. Februar 1791 starb er am 5. März 1811 und liegt in der Abteikirche neben dem ersten Abte Adam begraben. Exordium et tinis nobilis Ebraci, schrieb ein Angehöriger des Klosters, hic simul junguntur et uno quasi tumulo clauduntur! O fata rerum creatarum! Er verdiente wohl eine würdige Biographie. Seine Schriften sind: Bargildi Franconis disquisitio de ducatu et judicio provinciali Episcopatus Wirceburgensis, in ordine ad valorem argumenti praesumptae ex situ Superioritatis territorialis 1778148 SS. in 4. - De milite nobili et ingenuo saec. XI. et XiI. una cum vindiciis Marquardi de Grumbach dynastae. Norimbergae. 1794. 8. 118 SS. (gegen J. A. Samhaber's Abhandlung de statu et nominibus militarium in Germania. Wirceb. 1793). - Geschichte der deutschen staatsbürgerlichen Freiheit oder der Rechte des gemeinen Freyen, des Adels und der Kirchen Deutschlands. Bamberg und Würzburg. 1812 u. 14. 2.Bde. 8.

Der Verfasser starb nach dem Druck der ersten Bogen; die Herausgabe des bedeutenden Werkes, der Grundlage der zunächst folgenden deutschen Staats- und Rechtsgeschichten, besorgte F. A. Frey. Für seine Abtei schrieb Eugen Montag 2 Werke: Frage: Ob der Abtei Ebrach in Franken das Prädikat Reichsunmittelbar 
rechtmässig gebühre, und ob dieselbe als Herrschaft ihrer Unterthanen die Regel der Reichsfreiheit gegen die hochfürstl. Würzburgische Ansprüche einer vollkommenen Landeshoheit zu behaupten befugt seie? Erläutert aus der Geschichte, Privilegien, Verträgen und hauptsächlich aus dem Grund der noch unverrückt bestehenden Kayserlichen und Reichsohnmittelbaren Principal-Advocatie auf diese Abtei und derselben Unterthanen, in Gegensatz der so betittelten Caussa Herbipolensis und anderer Würzburg. gedruckten Streitschriften. Mit Beylagen Num. I-LXXII. 1786. fol. Das Handexemplar des Verfassers, das sich in meinem Besitze befindet, enthält viele Zusätze.

Die Veranlassung zu dieser gelehrten und überzeugenden Deduction gab, wie die Vorrede ausführt, das alles Maas überschreitende Verfahren der würzburgischen Regierung gegen den Abt ron Ebrach, als ein Angehöriger des Klosters die Keckheit gehabt hatte, auf dem Titel seiner Schriften sich „Profess des unmittelbaren Reichsstifts Ebrach" zu nenuen. Ehe der Streit über die Reichsunmittelbarkeit zu Ende war, traf beide, Kloster und Hochstift, 1802 das Loos der Vernichtung.

Der Streit mit Würzburg beginnt schon unter dem Bischof Lorenz von Bibra 1497, dauerte bis zur Säkularisation und rief verschiedene Streitschriften und damit den Druck der wichtigsten Urkunden hervor. Die Visitation des Klosters 1530, durch den eifrigen Biscbof Conrad von Thïngen, deren acta in's erzbischöfliche Archiv nach Mainz und mit demselben nach dreihundert Jahren wieder nach Würzburg gekommen sind (Mainzer Archiv-Bücher verschiedenen Inhalts No. 12), lässt den Zustand der Abtei, freilich kurze Zeit nach der furchtbaren Verwästung durch den Bauernkrieg, in trauriger Lage erscheinen. In der Streitsache über die Landes- und Reichssteuern betrat das Kloster unter Alberichs Nachfolger, dem Abt Ludwig, den Rechtsweg, wofür der gelehrte Syndicus desselben, Joh. Heinr. Weisenborn, die conclusiones aliquot juridicae um 1690 in einem starken Folianten herausgab, dem dann der Bischof Johann Gottfried 1692 in der Causa Herbipolensis entgegentreten liess. Zahlreiche urkundliche Belege finden sich in beiden Werken. Nach 10 Jahren wurde die Sache friedlich ausgeglichen.

Nicht so in einem andern berühmt gewordenen Streit. Der Abt Wilhelm hatte auf Veranlassung seines Ordensgenerals eine 
kurze Geschichte des Klosters drucken lassen unter den Titel: Brevis notitia Monasterii B. V. M. Ebracensis sacri ordinis cisterciensis in Franconia. Ex probatis authoribus, tum impressis, tum scriptis, originalibus Diplomatibus, antiquis Documentis et Scripturis desumpta et in hunc ordinem redacta a quodam ejusdem Loci et Ordinis Religioso. Anno 1738. Ohne Druckort und Verleger. 183 SS. Text in 4. Die würzburger Regierung fand sich durch diese Schrift so beleidigt, dass sie verboten, das Verbot durch Trommelschlag verkündigt, das Buch öffentlich zerrissen und verbrannt und der Ebrachische Anitmann als. dessen Verbreiter aus der Stadt gewiesen wurde. Der Abt brachte aber eine Beschwerde gegen dieses Verfahren nach Rom, wo dasselbe als incompetent erkannt und gestattet wurde, eine neue Auflage des Buches in Rom zu veranstalten. Diese Ausgabe auf 220 SS., die mit der ersten ganz übereinstimmt, ist in Franken sehr verbreitet, während die verbrannte zu einer literarischen Seltenheit geworden ist. Vernünftiger war der zweite Weg, welchen der Bischof von Würzburg dagegen einschlug; er liess durch seinen Syndicus Nic. A. Seitz eine diplomatische Widerlegung drucken unter dem Titel: Analysis libri: Brevis notitia, Accedit summarium aliquot documentorum. Anno 1740. Wirceb. fol.

Die nächste Streitschrift war die genannte von Eugen Montag. Ein zweites, noch ungedrucktes Werk desselben über Ebrach befindet sich im k. Kreisarchiv zu Würzburg (M. S. 24): Historiae diplomaticae Ebracensis Monasterii Saeculi I Epocha I ab anno 1126-1166 sive de rebus gestis sub Adamo Abbate I. Pro Aris Divisque Ebracensibus, F. E. A. 1794-95. Nunquam Typis. Handschrift des Verfassers 450 SS. in fol. Es besteht diese vortreffliche Arbeit aus der Vorrede, der geschichtlichen Darstellung 1-207, den diplomatischen Beweisen mit Erläuterung der einzelnen Urkunden, von 209-333, und 3 Excursen über den Zustand Deutschlands unter Conrad III, (1-37), über das mittelalterliche Münzwesen (41-77) und über den literarischen Verkehr des Abtes Adam mit der $\mathbf{h}$. Hildegarde $(81-117)$. Dass er im Sinne hatte, das Werk in günstigerer Zeit fortzusetzen, geht aus einer Aeusserung am Schlusse desselben hervor. Ueber das "nunquam typis" spricht er sich am Schlusse der Vorrede aus: „Caeterum quae scripsi, notitiae dumtaxat privatae, confratrum usui, et domesticae informationis causa scripsi. Insipienter ageretur, multumque noceret, si, quae candide hic confratrum intimata prudentiae ac fidei, in publicum vulgari vellent aut extraneis 
communicari. Typis nunquam haec, utut limatus accedat calamus, spargenda, maxime dum Jurisdictionis cum potentibus Adversariis dissidia fervent, qui candore Scriptoris facillime in malum abuterentur." Der letzte Grund ist nun freilich in Folge der Säkularisation weggefallen; aber ein einfacher Abdruck des Buches möchte jetzt nicht mehr an der Zeit sein; wohl,aber bildet es eine treffliche Vorarbeit für eine wissenschaftliche Verwerthung des reichen Quellenmaterials über Ebrach, wofür eine kleine Arbeit eines Freundes des gelehrten Abtes, des letzten Ebrachischen Kanzleidirectors P. W igand Weig a n d, Geschichte der Fränkischen Cistercienser Abtei Ebrach. (Herausgegeben und mit Anmerkungen versehen von $A$. Ruland), Landshut 1834. 142 SS. eine gute Einleitung bildet.

Andere Hülfsmittel sind für die spätere Zeit ein Necrologium, das 1725 angelegt, bis zum Aufhören des Klosters reicht (in Würzburger Archiv M. S. 27.), das Repertorium des vortreff lich geordneten Archivs aus dem J. 1740 (das. M. S. 25), ein Supplement zur Notitia brevis, das Leben der 3 letzten Aebte enthaltend (Historischer Verein M. S. $q^{*}$. 16), ein Verzeichniss der Mitglieder des Klosters von der Stiftung an bis zum 18. Jahrh. (das. M. S. q. 46), von demselben Verfasser eine tabellarische Uebersicht der Klostergeschichte im 1. Jahrhundert (das. M. S. q. 13) und ein Schlüssel zum Bibliotheks-Katalog aus dem J. 1788 (das. M. S. q. 15). Man sieht daraus, dass in der Bibliothek auf Ordnung gehalten wurde. Ein Theil der Bücher ist in die Universitätsbibliothek zu Würzburg gekommen, der grösste Theil aber verkauft worden. Was an Pergamenthandschriften einst vorhanden war, hat Ruland mitgetheilt S. 135 der Geschichte von W. Weigand. Darunter gehörten auch die wichtigen Aufzeichnungen des Michael vom Löwen aus dem Jahr 1350, die jetzt im k. Archive zu Würzburg aufbewahrt werden. (M. S. 6). Früher mochte die Bibliothek auch die Arbeiten eines der Angehörigen des Klosters, der einer der kunstvollsten Schreiber seiner Zeit war, des Sigfried Kalb, enthalten, von dem Ebert, Zur Handschriften-Kunde, Leipzig 1825, I, 153 folgendes mittheilt: „Schlimmer hat ein Schreiber wohl schwerlich seine Witz büssen müssen, als der ehrliche Klosterbruder Sifridus Vitulus oder Kalb in Ebrach, der in einem im J. 1315 geschriebenen Pergamentcodex der lateinischen Bibel (jetzt in Wolfenbüttel. 1. 3. 1. Ms. Aug. fol.) zur Seite sich selbst mit Anspielung auf seinen (zum bessern Ver- 
ständniss ausdrücklich beigesetzten) Namen als ein Kalb im Yönchsgewande, an einem Pult schreibend abbildete. Als der sächsische Ieibarzt Erndl im J. 1707 die Bibliothek besuchte, wurde ihm von einem Unterbeanten der Codex alles Ernstes als von einem Monstrum geschrieben vorgelegt, und der Leibarzt hatte dabei so wenig Arg, dass er in seiner Relatio de itinere suo Anglicano et Batavo (S. L. 8. S. 5) diese Merkwürdigkeit ebenso ernsthaft weiter an das Publikum berichtete, bis Burckhardt (Betulii epistola ad amicum. Hannov. 1710. 8. S. 60 ff.) umständlich und mit vielen Citaten bewies, dass man von einem solchen Monstrum doch noch kein Beispiel wisse." Auch in der Würzburger Universitätsbibliothek findet sich ein schön geschriebener Pergamentcodex aus dem J. 1312 vor von diesem berühmten Frater Sifridus Vitulus, scriptus sub Domino Friderico abbate.

Die Denkmäler in der Kirche zu Ebrach sind beschrieben und abgebildet in: P. Ign. Gropp, monumenta sepulchralia ecclesiae Ebracensis inprimis cordium episcoporum Wirceburgensium. Wirceb. 1730. 4.

sieḥe Neustudt am Main.

\section{Binsiedel,}

Engelgarten, Karthaus e zu Wü rz burg,

gegründet 1348 durch die Brüder Rüdiger und Wolfram, genannt Teufel, auf ihrem Anwesen, dem Teufelsgarten, und bis zur Säkularisation 1802 bestanden; jetzt stehen auf dem Boden derselben der alte Eisenbahnhof und Privatgebäude.

Uebrig sind noch 100 Urkunden, 11 aus dem 14. Jahrhundert, darunter die Bestätigung Bischofs Albert von 1351, 14 aus dem 15. Jahrhundert, die anderen 75 aus späterer Zeit bis 1787 ; ferner ein umfassendes Copialbuch (No. 243. 244) in zwei starken Bänden, Fol. Pap., im J. 1498 begonnen und Seite für Seite von dem kaiserlichen Notar Steinbach 1626 vidimirt; dann ein Copialbuch verschiedener Verhandlungen und Korrespondenzen nach Orten aus dem 17. und 18. Jahıhundert No. $244^{*}$; endlich ein Lehenbuch über verschiedene Ortschaften aus dem J. 1516. No. 647.

Der historische Verein besitzt die Rechnungen des Klosters aus den J. 1623, 76, 88, 1710, 84, 85 (M. f.* 153) und die Austausche desselben zu Estenfeld von $1756 \rightarrow 58$ (M. S. f. 305). 
Contzen :

\section{Frauenaurach,}

Dominikaner-Frauenabtei, am Einfluss der Aurach in die Regnit\%, im Bezirksamt Erlangen in Mittelfranken, gegründet 1275 von Herdegen von Grundlach und seiner Gemalin Elisabeth und 1552 säkularisirt.

Im k. Archiv zu Bamberg sind 23 Urkunden verwahrt, davon 20 aus dem 15. Jahrhundert und 3 aus der folgenden Zeit. Im k. Archiv zu Nürnberg 10 Urkunden, davon 1 aus dem 13., 4 aus dem 15. und 5 ăus dem 16. Jahrhundert. Im Würzburger Archiv finden sich keiue Urkunden dieser Stiftung vor. - Chr. Oesterreicher, Geschichte von Frauenaurach. Bayreuth 1830. 8.

\section{Frauenbreitungen,}

Prämonstratenser Nonnenkloster, an der Werra im Herzogthum Sachsen-Meiningen, im J. 1150 von den Grafen von Henneberg gegründet, im Bauernkriege 1525 zerstört und 1528 eingezogen.

Keine Urkunde ist im Würzburger Archiv mehr übrig. Das Diplomatar des Klosters ist gedruckt im III. Bande von Schöttgen und Kreissig, diplomataria \& scriptores historiae germanicae $1753-60$ fol.

\section{Frauenhausen,}

auch Bruderhart-, Bruder-Hartmanns-Zell genannt, oin kleines Frauenkloster, Prämonstratenser Ordens bei Hausen im württemberg. O.A. Gerabronn. Die Zeit der Gründung ist unsicher, angeblich durch Lupold von Bebenburg 1338, sein Ende fand es im Bauernkrieg. Der Ort heisst jetzt Klosterhof.

Urkunden haben sich im Würzburger Archiv keine erhalten.

\section{Frauenrode,}

Cistercienser Frauenkloster bei Kissingen, im J. 1231 ron dem Grafen Otto von Bodenlauben und seiner Gemahlin Beatrix gegründet und in Folge seiner Zerstörung in Bauernkriege 1525 aufgehoben. Aus diesem dreihundertjährigen Bestande haben sich 167 Urkunden erhalten, allein aus dem 13. Jahrhundert 47, aus dem 14.: 77, aus dem 15.: 34 und aus dem 16. Jahrhundert 9, deren jüngste vom J. 1557 ist. Auch ein sehr gutes Copialbuch ist erhalten aus dem J. 1587, dem am Schlusse ein älteres einverleibt ist. (No. 184.)

Die älteren Dokumente sind abgedruckt in L. Bechstein's schönem Werke: Otto von Bodenlauben. Leipzig 1845. 4. 
Franenthal,

auch Marienthal, Cistercienser Frauenkloster am Steinachbache östlich von Mergenthein, eine Stunde von Creglingen im Württembergischen, im J. 1232 durch die Grafen Godefried und Conrad von HohenloheBrauneck gegründet und durch die Bauern 1525 ganz zerstört und nicht wieder hergestellt.

Eine Urkunde ist im Würzburger Archive noch übrig vom J. 1232, worin B. Hermann den Stiftern die Pfarrei Münster (O. A. Mergentheim) übergibt (fehlt in von Langs Regesten), abgedruckt inı Württembergischen Urkundenbuch. Im k. Staatsarchiv zu Stuttgart sind keine Urkunden über dieses Kloster vorhanden.

Vergleiche Wibel, über das Kloster Frauenthal, in Oetter, Sammlung verschiedener Nachrichten. Erlangen. 1749 u. ff. S. 193, $482,629$.

\section{Georgenzell,}

im Grund der Rosa, im Herzogthum Sachsen-Meiningen, ein Cistercienser Mönchskloster, um 1310 durch Berthold von Wildprechtrode gegründet, im Bauernkriege 1525 zerstört und von HennebergSchleusingen 1531 säkularisirt.

Es ist keine Urkunde im Würzburger Archive mehr übrig. Vergleiche B r ü c k n e r, Landeskunde des Herzogthums Meiningen, I, Seite 90 u. 91 .

\section{Gerlachsheim,}

Prämonstratenser Kloster an der Tauber im Badischen, für Nonnen schon 1209 gegründet und Oberzell untergeben, im Bauernkriege 1525 so zerstört, dass der Bischof von Würzburg die Klostergüter einzog, um nicht auch diese zu verlieren, und sie 1717 dem Orden zurückstellte; seit 1724 war es dann ein Priorat und dauerte bis zur Säkularisation, in deren Folge der Fürst von Salm-Bedburg damit entschädigt wurde.

Urkunden sind keine mehr vorhanden, aber ein sehr gut um 1650 geschriebenes Copialbuch (No. 185), worin sich die Urkunden von 1187-1540 finden. Im historischen Verein sind Klosterrechnungen von 1689 und $1708-9$ und ein Catalogus defunctorum e Canonia Cellae Dei Superioris et Gerlachsheim aus dem vorigen Jahrhundert (M. S. o. 9).

S t u m p f (Denkwürdigkeiten. 1804. Heft III. S. 59-77) liess zehn Urkunden des Klosters drucken. 


\section{Gnadenthal,}

Cistercienser Nonnenkloster, im Königreich Württemberg, um das J. 1243 von Konrad ron Krautheim und seiner Gemahlin Kunigunde zuerst in Hohehach an der Jagst (O. A. Künzelsau) gegründet, aber schon vor 1246 nach Gnadenthal, Vallis Gratiae, an der Biber (O. A. Oehringen) verlegt, durch die Grafen von Hohenlohe reich dotirt, unter der Aufsicht der Abtei Schönthal stehend, in Folge der Reformation aufgehoben.

Erhalten haben sich an Urkunden aus dem 13. Jahrhundert 50 in fürstlichen Archiv zu Oehringen, 1 (1280, März 11) in Würzburg, aus dem 14.: 140 in Oehringen, aus dem 15.: 60 in Oehringen und eine (1483) in Würzburg. Im $k$. Staatsarchive zu Stuttgart finden sich keine Urkunden über dieses Kloster vor.

Dann ist noch in Oehringen ein Copialbuch; ein zweites, Papierhandschrift, befindet sich im städtischen Archiv zu Hall.

\section{Goldbach,}

ein Pauliner Eremitenkloster, zum Städtchen Waldenburg, O. A. Oehringen im Königreich Württemberg gehörig, im J. 1380 von Anna Landgräfin von Leuchtenberg, Wittwe des Grafen Kraft ron Hohenlohe, gegründet, mit der Reformation wieder aufgehoben.

Es war von Anfang an von geringer Bedeutung. Erhalten hat sich in Oehringen eine Originalurkunde vom J. 1388, in Würzburg eine vom J. 1470. Die übrigen, aber in geringer Anzahl, liegen in Waldenburg. Die Stiftungsurkunde fehlt. Auch im Staatsarchive zu Stuttgart ist keine Urkunde vorhanden.

Vergleiche Wibel, Hohenlohen. Kirchengeschichte I, 84. II, 330, 335. III, 128. IV, 63. Us sermann, Ep. Wirc. p. 504.

Grünau, Carthäuser-Kloster bei Wertheim,

Nova Cella genannt, um das J. 1328 gestiftet und bestanden bis 1626 .

Es findet sich in Würzburg nur eine Urkunde vor vom J. 1336, wodurch Bischof Otto die Pfarrei Eichel der neugegründeten Karthause incorporirt.

\section{Hall.}

In Schwäbisch-Hall (Königreich Württemberg) haben wir erstens ein Franziskaner-Conventualen- oder Barfüsser-Kloster, welches 1236 vom Abt Konrad von Komburg die S. Jakobskapelle daselbst erhielt und bis zur Zeit der Reformation bestehen blieb. 
Erhalten haben sich an Original-Urkunden Ablass-, Ginadenund Freiheitsbriefen, Kauf-, Vertrags-, Uebergabs-, Bestand- und Reversbriefen über des Klosters Zinsen, Gülten, Gefälle, auch Jahrtage aus dem 13. Jahrhundert 11 Stücke, aus dem 14.: 81, und aus dem 15.: 47, welche sich jetzt im k. Staatsarchive zu Stuttgart befinden. Im Würzburger Archiv ist keine Urkunde mehr vorhanden.

Wir finden dort zweitens ein Haus der willigen armen Schwestern oder Beguinen. Aus diesem Kloster sind noch übrig im Stuttgarter Archiv an Stiftungs-, Uebergabs-, Wechsel-, Urtheils-, Begnadigungs- und Erbbeständnissbriefen aus dem 14. Jahrhundert 21 und aus dem 15.: 20 Stücke, ferner ein Zinsregister ans dem 14. Jahrhundert.

\section{Hausen,}

Prämonstratenser-Frauenkloster, bei Kissingen; im J. 1161 von Heinrich Grafen von Henneberg gegründet, im Bauernkriege 1525 und dann wieder im Grumbachischen Kriege 1565 ganz zerstört, wurde es nicht wieder hergestellt, sondern die Einkünfte desselben von Bischof Julius seiner Universität zugewiesen.

Vorhanden sind noch 27 Urkunden, eine aus dem J. 1161 (gedruckt bei Grebner II, 49 und Ussermann 45), eine aus dem 13., 8 aus dem 14., 9 aus dem 15. Jahrhundert und die übrigen 8 später bis 1567.

Ein Copialbuch findet sich nicht vor. Der historische Verein hat die Klosterrechnungen aus mehreren Jahren des 17. Jahrhunderts. (M. S. f.* 158).

\section{Heldenfeld,}

Propstei regulirter Chorherren unweit Schweinfurt, in J. 1060 rom Markgrafen Hermann von Vohburg und seiner Gemalin Alberada von Banz gegründet; 1525 im Bauernkrieg und 1631 von den Schweden arg verwüstet, bestand sie blühend bis zur Säkularisation 1802. Ueber den Verlust ihrer Urkunden berichtet der letzte Probst Mauritius Trapp: „Die Stiftungsbriefe und Originalien seien nicht mehr vorhanden gewesen, denn Gustav Adolf von Schweden habe die Abtei der Stadt Schweinfurt geschenkt und das Archiv sei mit andern vorräthigen Sachen dahin abgeführt und in jener Zeit das meiste verloren worden; einer seiner Vorfahren habe bei Mäcklern daselbst verschiedene Schriften wieder aufgekauft; was noch vorhanden gewesen, sei wegen verschiedener Feindesgefahr öfters ein- 
und ausgepackt worden und in Unordnung gerathen und manches hiebei zu Verlust gegangen."

An Urkunden sind jetzt nur acht rorhanden, davon zwei aus dem 13., zwei aus dem 14., zwei aus dem 15. Jahrhundert und zwei aus der folgenden Zeit, darunter die letzte vom 10. A ugust 1805, dic den Verkauf des Klosters sammt allen dazu gehörigen Realitäten an den General-Landes-Commissär Grafen von Thürheim um die Summe von 102,500 Gulden betrifft.

Ein Copialbuch (No. 186) hat nur die Briefe vom 15. Jahrhundert an und ist im 17. zusammengetragen. Im historischen Verein ist ein Zinsbuch rom J. 1357, Perg. aufbewahrt und ein Necrologium, oder vielmehr Anniversarienbuch, aus neuerer Zeit, mit einem angehängten Verzeichniss der Pröbste (M. S. q. 77 u. f. 805).

Eine Geschichte des Klosters von Fr. Petri befindet sich in Michael Kuen, collectio Scriptorum. Tom. IV. p. 207 und daraus bei Ussermann p. 373 u. 374.

\section{Heldingsfeld.}

Bischof Hermann gestattet, nach der Urkunde von 1237, die Versetzung des S. Egidien-Convents daselbst auf einen bequemern Platz und gibt ihm den Namen Paradies und die Regeln des hl. Benedict.

Wahrscheinlich in Folge der Verwüstungen im Bauernkriege erlosch es allmählig, bestánd wenigstens im J. 1571 nicht mehr, und die Einkünfte wurden zur fürstlichen Kammer gezogen. Die Kirche mit vielen Grabmälern war aber noch vor hundert Jahren vorhanden. Jetzt hat sich auf der Stelle, wo einst das BenedictinerConvent adeliger Nonnen stand, seit dem J. 1855 ein Kloster der armen Schulschwestern mit einer Erziehungsanstalt erhoben.

Es sind nur noch 18 Urkunden vorhanden, 4 aus dem 13., 3 aus dem 14., eine aus dem 15. und 10 aus dem 16. Jahrhundert bis 1595, und an Büchern ein Zins-, Saal- und Lehenbuch aus dem J. 1528 (No. 187), dessen Verfasser auf die grosse Armuth der Klosterfrauen hinweiset; ein zweites vom J. 1571, worin sich die auf Befehl des B. Julius vom J. 1586 gefertigten Abschriften der damals noch vorhandenen Urkunden befinden (Kasten 11, -No. 148), und ein drittes vom J. 1605 (No. 188).

Klosterrechnungen aus den Jahren 1593-1724 besitzt der historische Verein (M. S. f.* 163). 


\section{Heilbronn.}

Siehe Carmeliten-Klöster.

\section{Heiligenthal,}

Cistercienser-Frauenabtei bei Schwanfeld, (Bezirksamts Schweinfurt) in J. 1234 gegründet, der Abtei Bildhausen unterordnet und im .J. 1564 erloschen; die Einkünfte verwandte B. Julius mit päpstlicher Bewilligung für sein neugestiftetes Spital; die Klostergebäude mit hübscher Kirche sind jetzt Privateigenthum.

An Urkunden sind noch 65 vorhanden und $z w a r 13$ aus dem 13., 38 aus dem 14, 8 aus dem 15. und 6 aus dem 16. Jahrhundert.

Ein Copialbuch hat sich nicht erhalten.

Aus den Urkunden schrieb Herr Professor Dr. Lippert eine lesbare Geschichte des Klosters, aber ohne Regesten, im IV. Bande des historischen Vereins, Heft 3. (1838). S. 39-53.

\section{Hildbarghansen}

erhielt im J. 1319 ein Collegiatstift mit zwölf Stiftsherrn und Priestern an der Pfarrkirche daselbst, gestiftet durch den Grafen Berthold VII. von Henneberg unter Bestätigung des Bischofs Godfried von Würzburg.

Der Stiftungsbrief vom 28. Juli 1319 ist erhalten.

\section{Himmelspforten,}

Cistercienser-Frauenabtei am Maine bei Würzburg, gegründet durch Bischof Hermann von Lobdeburg im J. 1231 zuerst in Himmelstadt am Maine, dann 1250 an jenen Platz versetzt, wo sie bestand bis zur Säkularisation im J. 1802. Die Gebäude, schöner Kreuzgang und Kirche im deutschen Stil, dienten den aus Russland rückkehrenden Truppen als Spital und sind jetzt ihrer ursprünglichen Bestimmung wiedergegeben, seitdem 1852 der Orden der Carmeliterinnen dieselben käuflich erworben hat.

Die Klosterfrauen hielten ihr Archiv in Ehren, die Urkunden und besonders die Siegel sind gut erhalten; doch fehlten schon nach dem amtlichen Berichte von 1804 bei Vergleichung mit den im Copeibuch verzeichneten 43 Originale; vorhanden sind noch 558, davon 94 dem 13., - die älteste ist der Stiftungsbrief vom J. 1231, von Bischof Hermann ausgestellt, - 274 dem 14., 92 dem 15. Jahr- 
hundert, die übrigen 98 bis zum J. 1781 der folgenden Zeit an gehöreu.

Auch die Copialbücher befinden sich im besten Zustande: das älteste (No. 189) in gross Folio enthält die Urkunden chronologisch und mit den Originalen collationirt bis zum J. 1527 und ist auch um diese Zeit, in der das Kloster viel im Bauernkriege zu leiden hatte, geschrieben; das zweite, ebenfalls vidimirte, hat die Urkunden nach Ortschaften vertheilt und ist zu Ende des 16. Jahrhunderts geschrieben, in zwei Bänden mit einem Nachtrag bis 1725 (No. 191 bis 193); ein kurzer Auszug aus letzterem gibt die Erwerbsgeschichte des Klosters (No. 190).

Kleinere Sachen über Himmelspforten befinden sich im Besitze des historischen Vereins. Ein Nekrologium, das noch zu Ussermanns Zeiten vorhanden war, (Cfr. Ussermann, Ep. Wirceb. p. 372), hat sich im Orginale nicht erhalten, befindet sich aber im Auszug in der handschriftlichen Ebracher Chronik des Joseph Agricola Tom. III. pag. 218-249. (Siebe Ebrach). Zu einer urkundlichen Darstellung ist bis jetzt auch nicht der Versuch gemacht worden.

\section{Hohebach,}

ist dasselbe wie Gnadenthal; siehe dieses.

\section{Hohenfeld,}

bei Kitzingen ami Main. Hier soll, nach Stieber, ein CistercienserNonnenkloster auf der Höhe gestanden sein, und ein Mönchskloster im Thale.

Ueberreste sind nicht mehr vorhanden; ebensowenig Urkunden.

IImbach,

Karthause am Steigerwalde, Hortus Mariae genannt, im J. 1453 von Balthasar Fehr von Bottig und seiner Gattin Magdalena von Vestenberg aus ihrer Burg gestiftet; im Bauernkriege zerstört und bald wieder hergestellt, dauerte sie bis 1802 .

Sie besitzt 154 Urkunden, davon 12 aus dem 14., die älteste von 1328, 54 aus dem 15. Jahrhundert, die übrigen 88 aus der folgenden Zeit.

Ein Copialbuch hat sich im Würzburger Archive nicht erhalten.

Eine Geschichte der Karthause schrieb nach einigen ihm zulgänglichen Hülfsmitteln G. Höfling im Archive des historischen Vereins Band VI, Heft 3, S. 65-127. Mit eilf Urkunlen. 
St. Johann unter Wildberg,

Cistercienser-Nonnenkloster unterhalb der Burg Wildberg, bei dem Dorfe Sulzfeld, zwei Stunden ron Königshofen im Grabfeld, angeblich im Anfange des 13. Jahrhunderts gestiftet, in Folge der Zerstörung durch den Bauernkrieg in der Mitte des 16. Jahrhunderts erloschen; auf der Stelle desselben steht jetzt das Oekonomiegut Johanneshof.

Erhalten haben sich 22 Urkunden, davon 4 aus dem 14., 13 aus dem 15. und 5 aus dem 16. Jahrhundert; die älteste vom J. 1303, Schenkung eines Zehnten durch Albert Kölner, die jüngste vom J. 1555, Inventar über den Inhalt einer dem Kloster gehörigen Truhe; dann ein Zinsbuch und Register über die zur fürstlichen Kammer gezogenen Gefälle dieses Klosters nebst einigen historischen Notizen und Urkunden aus dem J. 1579 (Nr. 197).

Das Beste über dieses Kloster befindet sich in Rost, Königshofen. Würzburg. 1832. S. 170 u. ff.

\section{ritzingen,}

Benedictinerinnen-Abtei, um 745 gestiftet und 1544 durch die Markgrafen von Ansbach, in deren Händen sich die Stadt Kitzingen pfandweise befand, aufgehoben. Das Archiv, welches nach Plassenburg geschafft war, musste, als die Stadt 1629 von Würzburg wieder eingelöset ward, in Folge eines kaiserlichen Hofrathsbeschlusses ausgeliefert werden. Die Benedictinerinnen-Abtei wurde nicht wieder hergestellt, dagegen errichtete Bischof Johann Gottfried im J. 1697 ein Ursuliner-Kloster für den Unterricht der weiblichen Juggend, welches bis zum J. 1802 bestand, und von dem 10 Urkunden, die jüngste von 1802 , im Würzburger Archive erhalten sind.

Von der Benedictinerinnen-Abtei sind noch 222 Urkunden übrig, 5 aus dem 11. Jahrhundert, - in der ältesten von 1007 schenkt K. Heinrich II. das Kloster der Bamberger Kirche, -12 aus dem 12., 19 aus dem 13., 41 aus dem 14., 121 aus dem 15. und 24 aus der folgenden Zeit; ferner ein kleines, schlecht erhaltenes Copeibuch aus dem 14. Jahrhundert, welches fünf Urkunden aus

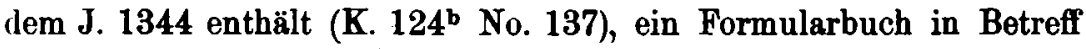
der Eidesleistungen der Beamten des Klosters und der Rechte desselben in der Stadt Kitzingen aus dem Anfange des 16. Jahrhunderts (No. 199), das sogenannte Würzburgisch Buch, die Reformation und Ordnung im Kloster betreffend, mit dem deshalb gepflogenen Briefwechsel aus den J. 1493-94 (No 200), die Saalbücher vom 
J. 1499 (No. 202), (das des Spitals zu Kitzingen, No. 204 ist aus demselben Jahr), besonders das vom J. 1519 (No. 204), worin sich von Blatt 196 an die Wappen der "Closterfrawen" befinden, "die ich Margaretha Eptissin geborne Truchsessen von Baldersheim unther meiner gehorsam gehabt hab, dieweil ich Eptissin gewesen bin," dann die Gült- und Zinsbücher ron den Jahren 1489 (No. 198), 1514, 1534 (No. $204^{\circ}$ ). Interessant sind die Briefe der Äbtissin Katherine von Fronhofen von 1524-31 zur Zeit des Bauernkrieges (No. 204*) und die Collectanea des Stadtschreibers zu Kitzingen Paul Rücklein, in den ersten Decennien des 17. Jahrhunderts zusammengeschrieben (No. 201). -

Die Urkunden über Kitzingsn von 1336-1628 enthält die Schrift Acta in Sachen Würzburg contra Brandenburg: Ablösung der Pfandschaft Kitzingen betreffend, 1629. Fol.

Unbedeutend ist Joh. Hesse historische Erzählung von dem Kloster und der Stadt Kitzingen, in Pistorius, amoenitates historicojuridicae. Frankfurt 1733. 4. Theil III. No. 8.

\section{Komburg,}

als Benedictinerkloster 1078 gegriłndet, 1488 in ein ritterliches; Collegiatstift umgewandelt und 1802 aufgehoben.

Erhalten haben sich an Original - Urkunden, päpstlichen und kaiserlichen Privilegien, Schutz- und Schirmbriefen, Mandaten, Stiftungsbriefen, Verträgen mit benachbarten geistlichen und weltlichen Fürsten und Städten, kaiserlichen Lehensbriefen, Lehensreversen u. s. w. aus dem 13. Jahrhundert 41 Stücke im k. Staatsarchive in Stuttgart, aus dem 14.: 169 zu Stuttgart, 2 in Würzburg; aus dem 15. Jahrhundert 279 in Stuttgart, 3 in Würzburg, wo sich auch noch 16 spätere bis zum Jahre 1688 nebst der Copie einer Urkunde von 1137 befinden. Im Stuttgarter Staatsarchiv sind ferner aufbewahrt eine Statutensammlung von 1489 , dann 20 theils grössere theils kleinere zum Theil aus mehreren Bänden bestehende Diplomatarien mit Urkunden vom 11. Jahrhundert an, ein Saalbuch aus dem 15. Jahrhundert, ein Lagerbuch über die Gülten des Klosters von 1478, mehrere Lehen- und Eidbücher, Vorladungen der Lehenleute zum Lehengericht $u$. A. Mencke gab in den Script. rer. germ. Tom. I diplomata Chomburgensia, H. B a u er 12 andere in der Zeitschrift für das württembergische Franken (1863) VI, 280. 
Eine Bearbeitung der Kloster- und stiftsgeschichte fehlt; Beiträge lieferten: Prescher, Geschichte der Reichsgrafschaft Limburg 1, 205. II, 375 u. ff. - Usserm an n, Episc. Wire. pay. 198-212. staelin, württembergische Geschichte I, 591. II, 700.

\section{Königsberg,}

Augustiner Eremitenkloster, zwei Stunden von Hassfurt in der Sachsen-Coburgischen Enklave gelegen, un die Mitte des 14. Jahrhunderts gegründet, von der Aglaienschwester-Gesellschaft zur Stiftskirche gewählt, im Bauernkriege 1525 zerstört, bei welcher Gelegenheit die Dokumente nach Coburg geflüchtet (nach Anderen aber zerstört wurden), und bald darauf säkularisirt.

Eine Urkunde hat sich im Würzburger Archiv nicht erhalten, im historischen Vereine eine vom J. 1536 (M. S. q. 94), die das Einkommen des Klosters betrifft.

Cfr. Ussermann p. 505. - Schulte's Coburgische Landesgeschichte S. 82. - Kra u se Hildburghausen. Landeshistor. Thl. IV. S. 107 u. ff.

\section{Ereutsfold,}

jet»t Weiler; zum Pfarrdorf Schrozberg gehörig, württembergischen 0. A. Gerabronn, hatte ein Frauenkloster, welches durch Bischof Hermann im J. 1253 mit dem Kluster Scheftersheim vereinigt wurde.

Urkunden aus der Zeit vor der Vereinigung haben sich keine erhalten.

\section{Itirnach,}

Cistercienserinnenkloster, (zwei Stunden nordöstlich von Würzburg), ron dessen Existenz noch eine einzige Originalurkunde vom J. 1291 Zeugniss gibt. Anfang und Ende dieser Stiftung sind unbekannt.

\section{Lambach,}

Benedictiner-Abtei an der Traun, in Oesterreich ob der Enns, vom Würzburger Bischof Adalbert auf dem väterlichen Erbe 1056 gestiftet, mit dem fränkischen Hochstift in früherer Zeit vielfach in Verbindung, bewahrt noch mehrere sehr gut erhaltene Würzburger Urkunden auf, die im IV. Bande des Urkundenbuchs des Landes ob der Enns (1867) gedruckt sind. Die Abtei besteht noch.

Vergleiche Dr. P. Schmieder breve chronicon monasterii b. Mariae virg. Lambacensis 1865. 8 und dessen Notizen zur älteren 
Baugeschichte der Stiftskirche und des Klosters zu Iambach mit 12 Holzschnitten. Wien 1866. 4. Vergleiche auch die vita Adalberonis und die Nekrologien:

\section{Langenzenn,}

Kloster von Regular-Canonikern Augustiner Ordens, in Städtchen dieses Namens an der Zenn, $\mathbf{k}$. Bezirksamts Kadolzburg in Mittelfranken, im J. 1409 durch die Burggrafen Johann und Friedrich von Nürnberg gegründet und 1527 von ihren Nachkommen säkularisirt.

Im 1. Archive zu Bamberg sind 317 Urkunden aufbewahrt, davon 235 aus dem 15. Jahrhundert, 80 aus der folgenden Zeit und zwei ohne Datum; im k. Archive zu Nürnberg 55 Urkunden, wovon 34 dem 15. und 21 dem 16. Jahrhundert angehören; dann ein Nekrologium und zwei Saalbücher aus dem 16. Jahrhundert. Im k. Archive zu Würzburg ist nur eine Urkunde aus dem J. 1418 vorhanden. Vergl. Ussermann p. 484.

\section{Laufen,}

am Nekar im Königreich Württemberg, O. A. Besigheim, Benedictiner Nonnenkloster, im J. 1003 vom Bischof Heinrich ron Würzburg gestiftet, durch die Reformation aufgehoben, nachdem es seit der Mitte des 13. Jahrhunderts Dominikanerinnen und seit 1466 die Prämonstratenserinnen von Adelberg innegehabt.

An Urkunden haben sich erhalten im k. Staatsarchive ॥ $^{\prime \prime}$ Stuttgart aus dem 13. Jahrhundert 10 Stücke, aus dem 14.: 35 und aus dem 15.: 39 Stücke; im Archive zu Würzburg ein Revers von 1477 .

\section{Lichtenstern,}

Cisterzienser-Nonnenkloster, im Königreich Württemberg zum Städtchen Löwenstein gehörig, 0. A. Weinsberg, am Ursprunge der Sulm in einen hübschen Waldthale gelegen, gestiftet im J. 1242 durch Luitgardis, Wittwe Engelhards von Weinsberg, geborne von Limpurg. Bischof Hermann bestätigte 1243 die Stiftung und gab ihr den Namen Praeclara Stella, sonst gewölnulich Clara Stella genannt. Yon den Bauern 1525 zerstört und dann 1554 gewaltsam aufgehoben, dient es jetzt zu einer Kinderrettungs- und Bildungsanstalt für freiwillige Armenschullehrer.

Erhalten haben sich an Urkunden im k. Staatsarchive zu Stuttgart aus dem 13. Jahrhundert 5 Stück, aus dem 14.: 8 und 
alls dem 15.: 17 stück. Im Wür\%burger Archiv ist keine vorhanden. II one theilte in seiner Zeitschrift XI, 344-68 15 Urkunden mit.

Vergl. Ussermann, Ep. Wirc. p. 470. - Staelin, Wirtt. Ciesch. II, 723. Eine Uebersicht der Geschichte gibt das Schriftchen von Chr. Eichen hofer, Lichtenstern als Frauenkloster, Oberamtei und Anstalt. Heilbronn 1867. 12.

\section{Loehgarden,}

Prämonstratenser Frauenstift, im Königreich Württemberg, heut zn Tage Louisgarde im O. A. Mergentheim, gestiftet im J. 1144 von zwei Lorcher Chorherrn, Constantin und Giselbert, und bereits im 14. Jahrhundert dem nahegelegenen Kloster Scheftershein einverleibt. Weder im Würzburger noch im Stuttgarter Archive ist eine Urkunde über dieses Kloster vorhanden.

Maidbranp, Fons S. Mariae,

Cisterzienser-Frauenabtei, bei Rimpar, zwei Stunden von Würzburg, im J. 1232 von Bischof Hermann gestiftet, im Bauernkriege 1525 zerstört und nicht wieder hergestellt; die Einkünfte sind dem Juliusspitale zugewiesen. Die kleine Klosterkirche birgt noch jetzt ein Kunstwerk von grossem Werth, die Grablegung Christi von Tilemann Riemenschneider.

Von Urkunden haben sich 71 erhalten, 17 aus dem 13., darunter die Stiftungsurkunde in drei Exemplaren, 18 aus dem 14., 9 aus dem 15. Jahrhundert und 27 aus der folgenden Zeit. Ein vidimirtes Copialbuch in zwei Foliobänden verdanken wir der Regierung des Bischofs Julius (No. 211 und 212). Fünf Urkunden gab Stumpf heraus in den Denkwürdigkeiten (1802). Heft 1. S. 86-97.

\section{Mariaburghausen,}

Cisterzienser-Franenabtei, am Maine gegenüber von Hassfurt, gegründet 1237 und, nachdem es durch die Stürme des 16. Jahrhunderts verödet worden, in J. 1582 von Bischof Julius eingezogen und ihre Einkünfte der neugegründeten Universität zugewiesen. Die guterhaltene Klosterkirche sehenswerth.

Uebrig sind noch 189 Urkunden, davon 48 aus dem 13., 90 aus dem 14., 31 aus dem 15. Jahrhundert, 18 aus dem 16. bis 1554 und zwei spätere. 
Wichtig sind die erhaltenen zwei Copeibücher, beide in der Registratur des Verwaltungsauschusses der $k$. Universität, das eine aus der ersten Hälfte des 15. Jahrhunderts, aus 38 Pergamentblättern bestehend, wovon der historische Verein eine durch den Historiker Johannes verfertigte sehr uncorrecte Abschrift besitzt, umfasst 168 Urkunden (70 aus dem 13., 88 aus dem 14. und 10 aus dem 15. Jahrbundert), welche topographisch geordnet sind; das zweite, auf Befehl des Bischof Julius geschrieben und durch seinen Oberregistrator Mag. Martin Zink 1586 mit den Originalien collationirt, umfasst dagegen 253 Urkunden (76 aus dem 13., 116 aus den 14., 43 aus dem 15. und 18 aus dem 16. Jahrhundert), darunter 42 von Würzburger Bischöfen. Hier ist die chronologische Ordnung strenge durchgeführt.

Geschichten des Klosters veröffentlichten: $\mathrm{J}$ a eg er (1836) im III. und eine bessere J. Denzinger (1850) in $X$. Bande des Archivs des historischen Vereins zu Würzburg.

Die Bearbeitung der Regesten wäre auch hier sehr wünschenswerth.

\section{Mariencapell.}

Siehe Carmelitenklöster.

\section{Marienthal}

ist dasselbe mit Frauenthal; siehe dieses.

Marxerkloster zu Würzburg,

oder das Kloster der Dominikanerinnen ad S. Marcum. Erst dem Augustinerorden angehörig wurden die Klosterfrauen durch eine Bulle P. Innocenz IV. vom J. 1245 ermächtigt, in den neugegründeten Orden des hl. Dominikus einzutreten. Sie zählten zu Mitschwestern Angehörige der höchsten Stände; so lebte hier die Wittwe König Heinrichs VII., Margaretha, nach dem Tode ihres Gemahls 1242 bis zu ihrer zweiten unglücklichen Vermählung mit König Ottokar von Böhmen im J. 1252, so die Wittwe Otto's von Bodenlauben, Adelheid von Hildenburg, und Andere. Das Kloster bestand bis zur Säkularisation im J. 1802 und ist jetzt zu Privatwohnungen verwendet.

Im Ganzen haben wir nur 37 Urkunden übrig, die älteste ist vom 1. Mai 1244, worin Bischof Hermann auf Fürbitte dominae nunc sororis Margaretae, quondam Romanorum reginae illustris, 
quae in paupertate elegit Domino famulari, das Kluster in seinen Schutz nimmt; von den übrigen sind 5 aus dem 13., 3 aus dem 14 . 2 aus dem 15. Jahrhundert und 26 aus späterer Zeit. Die geringe Anzabl der erhaltenen Urkunden erklärt sich aus dem Úmstande, dass bei dem zweimaligen Brande des Klosters in den J. 1638 und 1644 viele Diplome zu Grunde gingen.

Einigen Ersatz liefert ein deutlich geschriebenes Copialbuch: Yidinirte Copien der Originalien über die Brieff und Gerechtigkeitten des Closters zu Sanct Marx, Predigerordens zu Würzburg, abgeschrieben und vidimirt Anno 1594 (No. 209). Die deutschen Urkunden darin sind von einer Klosterschwester Sabina Barbara Lutz abgeschrieben und von dem kaiserlichen Notar Erasmus Lamprecht vidimirt worden.

Ausserdem sind noch vorhanden einige Lehenbücher über die Grundzinsen des Klosters aus den Jahren 1466, 1474, 1479 und 1586 (No. 205-8) und im historischen Verein ein Hausbuch nebst den Rechnungen' aus den Jahren 1676-81 (M. S. q. 57 u. f. 276).

\section{Meckmilihl,}

oder Möckmühl, am Einfluss der Seckach in die Jaxt, in Württenberg, im 0. A. Neckarsulm, ein Chorherrnstift, im J. 1379 durch die Grafen Kraft und Gottfried von Hohenlohe gegründet und vom Bischof Gerhard am 8. August desselben Jahres bestätigt.

Erhalten haben sich an Stiftungsbriefen und Confirmationen von Stiftungen, an Kauf-, Lehens-, Uebergabsbriefen, an Verträgen II. s. w. aus dem 14. Jahrhundert 4 und aus dem 15. 70 Urkunden im k. Staatsarchiv zu Stuttgart; daselbst ferner ein Statutenbuch des Stifts von 1484, ein Zinsbuch von 1499 und eine Copiensammlung aus dem 16. Jahrhundert mit Abschriften von Urkunden aus diesem und dem 15. Jahrhundert.

\section{Kelningen.}

Hier ward 1239 ein Franziskanerkloster gestiftet, das bis zur Keformation bestand und 1543 aufgehoben wurde.

Urkunden davon finden sich im Würzburger Archive nicht vor.

Mergentheim, an der Tauber,

im Königreich Württemberg, früher Sitz der Hochmeister des deutschen Ordens, mit einem vorzüglichen Archive, das sich seit dem J. 1868 in Ludwigsburg befindet. Es hatte auch seit dem J. 1273 
ein Dominikanerkloster, wovon sich nur noch aus den 14. Jahrhundert zwei und aus dem 15. eine Urkunde im $k$. Statsarchive zu Stuttgart erhalten haben.

\section{Michelfeld,}

Prämonstratenser-Nonnenkloster, bei Kitzingen, in J. 12b1 gegründet und 1305 von den Nonnen verlassen, die nach Tüickelhausen übersiedelten.

Keine Urkunde hat sich erhalten.

\section{Mistlan,}

Benedictiner-Nonnenkloster, zum Pfarrort Gaggstadt, O. A. Gerabronn in Königreich Württemberg, gehörig, im J. 1282 von Elisabeth Gemahlin des Grafen Godfried von Hohenlohe gestiftet und wegen Mittellosigkeit 1479 mit Comburg vereinigt.

Urkunden haben sich keine erhalten. Cfr. Usserman n p. 450 .

Monehauraeh, an der Aurach,

k. Bezirksamts Höchstadt in Oberfranken, Benedictinerabtei, gestiftet um 1110 von Goswin Grafen von Höchstadt, Vater des Pfalzgrafen Hermann, im Bauernkriege zerstört und von dem Markgrafen von Ansbach eingezogen.

Uebrig sind im k. Archiv zu Bamberg 48 Urkunden, davon 39 aus dem 15. Jahrhundert, 9 aus der folgenden Zeit: im $k$. Archive zu Würzburg zwei Urkunden von 1156 und 1457, die erste bei Ussermann Cod. prob. no. XL. gedruckt.

Im k. Archive zu Nürnberg findet sich ein Copialbuch mit den Urkunden aus der Zeit von 1480 bis 1624.

Vergleiche G. L Lehnes, Geschichte von Mönchaurach. Neustadt 1837.

\section{Mönchröden,}

Benedictiner-Abtei, zwischen Coburg und Neustadt an der Heide, im J. 1148 gegründet, von den Baueru 1525 zerstört und nicht wieder hergestellt.

Nichts hierüber vorhanden. Die Urkunden in Schöttgen und Kreysig diplomat. Tom. III. - Cfr. Schultes, Henneberg. Gesch. I, 238. 255 und dessen Coburg. Landesgesch. des Mittelalters 1814. S. 79. 


\section{Mönchsteinach,}

Benedictiner-Abtei, in k. Bezirksamt Neustadt an der Aisch in Yittelfranken, im J. 1102 gestiftet von Albrecht von Steinach und seiner Gemahlin Adelheid von Burleswag, in Bauernkriege geplündert und 1529 säkularisirt von dem Markgrafen Georg dem Frommen. Erhalten haben sich im k. Archive zu Bamberg 11 Urkunden, davon 3 aus dem 15. Jahrhundert und 8 aus der folgenden Zeit; im Archive zu -Würzburg zwei Urkunden aus den J. 1345 und 1353.

Vergl. Ussermann l. c. pag. 423 und G. L. Lehnes, Geschichtliche Nachrichten von den Orten und Klöstern Riedfeld, Mönchsteinach und Birkenfeld. Neustadt a/A. Lief. II. S. 100-116.

\section{Mosbseh,}

an der Einmündung des engen Thals der Elzbach in das schöne Neckarthal, Reichspfandschaft, dann im Besitze der Pfalzgrafen und von 1410-1499 fürstliche Residenz, jetzt badische Amtsstadt, hatte eine schon 976 urkundlich (im Diplome König Otto's II. bei Ussermann Ep. Wirc. cod. prob. pag. 118) erwähnte Benedictiner-Abtei, die seit dem Anfange des 13. Jahrhunderts als Collegiatstift erscheint, welches 1258 dem Bischofe zu Würzburg das Recht überträgt, einen Probst aus seinem Domcapitel nach Mosbach zu setzen. Es wurde durch den Kurfürsten Friedrich III. von der Pfalz 1564 aufgehoben.

Die Urkunden sind zerstreut; was sich erhalten hat, befindet sich theils im städtischen-Archiv auf dem Rathhause zu Mosbach, wo augh das Copeibuch des Stifts (jedoch ohne ältere Urkunden vor dem 14. Jahrhundert) auf bewahrt ist, theils-im GenerallandesArchiv zu Carlsrube, theils im Archive zu Würzburg; letzteres hat noch zwei Urkunden aus dem 13. Jahrhundert, 2 aus dem 14., 3 aus dem 15. und 10 aus der spätern Zeit.

Die beiden ersteren Archive sind benutzt in der Schrift: Die Stadt Mosbach, historisch, topographisch und statistisch geschildert von $\mathrm{H}$. Wirth, Heidelberg, 1864, 8., wodurch die ältere ohnehin unbedeutende Literatur: J. H. Andreae, Mosbacum illustratum s. I. 1771. 4. 28 pag. - Widder, Beschreib. der Pfalz II, 76 u. ff. Ussermann, Ep. Wirc. p. 264 und 441 überflüssig geworden ist.

\section{Mtinnerstadt.}

Siehe Deutscher Orden und Augustinerklöster. 


\section{Murrhardt,}

in Königreich Württemberg, 0 . $A$. Backnang, Benedictinerkluster. schon zur Zeit der Karolinger gestiftet, 1509 in ein Chorherrnstift verwandelt, 1534 durch Herzog Ulrich eingezogen und seit 1552 mit protestantischen Aebten besetzt.

Im k. Staatsarchiv zu Stuttgart befinden sich noch aus dem 14. Jahrhundert 3 und aus dem 15.: 13 Originalurkunden, dani das sog. rothe Buch des Klosters Murrhardt oder Beschreibung desselben und seines Einkommens von dem Abt Johann Hummel aus dem J. 1600.

Im Würzburger Archiv befanden sich zwei Urkunden von 1475 und 1520 und mehrere Aktenstücke, die Reformation des Klosters und die Wahl des letzten katholischen Abtes betreffend ron 1500 bis 1552 , die jetzt an Württemberg abgegeben sind.

Die Urkunde von 1509 über die Verwandlung des Klosters in ein Collegiatstift in Mone, Zeitschrift XI, 368.

Vergl. Staelin, wirt. Gesch. I, 370. 592. II, 691.

\section{Nenstadt, am Maine,}

die älteste Benedictiner-Abtei Frankens, im J. 783 gegründet und durch die Säkularisation aufgehoben; die Besitzungen wurden der jüngeren Linie des Hauses Löwenstein-Wertheim durch den Reichsdeputations-Hauptschluss zugewiesen.

Im k. Archive zu Würzburg befinden sich noch 12 Urkunden, eine aus dem 14., eine aus dem 15. Jahrhundert, die anderen aus der folgenden Zeit bis 1794; die übrigen Urkunden sind jetzt im fürstlichen Archive zu Wertheim. Die ältesten Stiftungs- und Dotationsurkunden sind unzuverlässig. Siehe Ussermann, Ep. Wirc. p. 325 und zuletzt $\mathrm{K}$ l ü b er, diplomatische Prüfung zweier Stiftungsund Ausstatungs-Urkunden, welche Kaiser Karl der Grosse in den Jahren 794 und 812 dem Benedictinerkloster Neustadt am Main ertheilt haben soll, in dessen Abhandlungen und Beobachtungen für Geschichtskunde, Staats- und Rechtswissenschaft. Frankfurt 1834. Band II, S. 310. Sie waren die Ursache der Irrungen zwischen den Bischöfen von Würzburg und den Aebten, die dahin führten, dass Bischof Friedrich 1558 alle Kloster-Urkunden seinem Archive einverleiben und Bischof Adam Friedrich, als das Kloster zur Führung eines Prozesses am Reichskammergericht innerhalb seiner Mauern die Neustadter Deduction gegen Würzburg hatte drucken 
lassen, im J. 1766 die Pressen gewaltsam aus demselben abholen liess. Ausser dieser Ausgabe der Urkunden haben wir zwei Copialbücher, eines unter Bischof Julius 1586 geschrieben, (No. 213), das andere unter Bischof Johann Gottfried 1690 durch Balthasar Wigandt, öfentlicher Notar, verfasst (No. 214); in beiden ist die Abschrift der einzelnen Urkunden beglaubigt.

Einige Urkunden gibt Mone, Zeitschrift 4., $406 \mathrm{u}$. ff.

Eine gute lesbare Monographie von J. A. Kraus, die Benedictiner-Abtei Neustadt am Main. Würzburg. 1856. Derselbe Verfasser machte schon 1847 zuerst auf die zum Kloster gehörige Probstei Einsiedel aufmerksam, die 1264 gestiftet bis 1485 bestand, in der Abhandlung: Urkundliche Nachrichten über das Kloster Einsiedel im Spessart, in Archive des historischen Vereins Band IX. Heft 3. SS. 122-139. Mit sieben Urkunden.

Neustadt an der Saale.

Siehe Carmelitenklöster.

Neustadt an der Aisch oder Bledfold.

Hier wurde 1459 ein Franziskanerkloster von den Markgrafen Johann und Albrecht von Brandenburg errichtet, das im Bauernkriege zerstört und nicht wieder hergestellt ward.

Urkunden darüber sind in Würzburger Archive keine vorhanden. Vergl. Riedfeld.

\section{Oohringen,}

Collegiatstift, gegründet 1037. Die Fundationsurkunde ist oft gedruckt, zuletzt im württembergischen Urkundenbuch I, 163; ein Facsimile derselben befindet sich bei Hanselmann, diplom. Beweis der Hohenloh. Landeshoheit I, 581; aufgehoben wurde es 1545 .

An Urkunden haben sich erhalten aus dem 11. Jahrhundert 1 (1037) im fürstlichen Archive zu Oehringen, aus dem 12. Jahrhundert 1 zu Oehringen, aus dem 13.: 5 daselbst, aus dem 14. ungefähr 140 zu Oehringen, 2 zu Würzburg, aus dem 15. eine grosse Anzahl in Oehringen, 4 in Würzburg, 1 in Stuttgart; aus der folgenden Zeit noch eine Menge in Oehringen, 3 (bis 1630) in Würzburg.

Literatur: Wibel, I, 45 und II, 134-162, wo ein Necrologium oder Calendarium mortuorum aus dem 15. Jahrhundert, 
wichtig für die Hohenlohesche Geschichte, abgedruckt ist, das sich nwh h unter dem Titel: Obleybuch des Stifts Oehringen, im fürstlichen Archir daselbst befindet. -- Vergl. die Nekrologien. - U s ser mann, Ep. Wirc. 256-63. - S taelin, wirtembergische Geschichte II, 743. - Aeltere Geschichte der Stadt und des Collegiatstifts Oehringen von Fromm und Bauer, in der Zeitschrift für das wirtembergische Franken. Jahrgang 1850 S. 8-39. - Geschichte und Beschreibung der Stiftskirche zu Oebringen von Jos. Albrecht. Mit einem Grundriss. Oehringen 1837. Dazu Bauer, die Stiftskirche zu Oehringen und ihre Antiquitäten, in der genannten Zeitschrift V, 2 (1860), S. 266-83.

\section{Rassdorf,}

Collegiatstift, wovon sich eine Urkunde vom 8. Dezember $1345 \mathrm{im}$ Archive zu Würzburg erhalten bat.

\section{Ređerinnenkloster zu Würzburg,}

ad S. Mariam Magdalenam, Cisterzienser Ordens, im J. 1227 gestiftet, 1286 erneuert und im 16. Jahrhundert erloschen. Bischof Philipp Adolf übergab die leeren Gebäude 1627 den unbeschuhten Carmeliten, die davon den Namen Reuerer tragen; Johaun Plilipp von Schönborn liess ihnen 1662 eine neue Kirche erbauen. Das Kloster besteht noch. Von dem ehemaligen Magdalenkloster sind noch 41 Urkunden da, 13 aus dem 13., 14 aus dem 14., 11 aus dem 15. Jahrhundert und 3 aus der folgenden Zeit bis 1540, ferner ein Lehen-, Zins- und Gültbuch aus dem J. 1502 (No. 262 ). Auch der historische Verein besitzt eine das Kloster betreffende Sammlung von Urkunden. (M. S. f. 164).

Vergl. Seidner, urkundliche Nachricht von dem ehemaligen Frauenkloster der s. g. Reuerinnen ad $S$. Magdalenam \%u Würzburg, mit 2 Urkunden von 1286 und 1327, in der Zeitschrift für Bayern, II, 5. Mai 1817. S. 217-237.

\section{Riedfold,}

gegenüber dem Städtchen Neustadt an der Aisch in Mittelfranken. Das hier im J. 1459 von den Burggrafen Johann und Albrecht gegründete Franziskanerkloster ward im Bauernkriege zerstört und auf dessen Stelle 1584 die Gottesackerkirche der genannten Gemeincle 
errichtet. Was sich erhalten hat, ist gesammelt ron L ssermann, I. c. pag. 510 und ron G. L. Lehnes, Geschichtliche Nachrichten von den Orten und ehemaligen Klöstern Riedfeld, Münchsteinach und Birkenfeld; Neustadt a/A. 1833, Lief. I. S. 69-96.

\section{Römhlld,}

früher gräflich-fürstliche, dann herzogliche Residenz und Hauptstadt des gleichnamigen Landes, jetzt Amtsstadt in Herzogthum SachsenMeiningen, hatte ein vom Grafen Georg von Henneberg 1450 gegründetes Collegiatstift mit einem Dechant und zwölf Chorherrn, das zur Zeit der Reformation eingezogen, die schöne Kirche in die Pfarrkirche verwandelt wurde.

In Archive zu Würzburg sind noch drei Urkunden aus den Jahren 1454, 1462 und 1470 übrig; die sonst erhaltenen werden sich in Gesammtarchiv zu Meiningen befinden.

\section{Scheftersheim,}

an der Tauber bei Weikersheim im Königreich Württemberg, ein Prämonstratenser-Frauenkloster, gegründet 1162 von Friedrich von Rotenburg, Sohn Kaiser Conrad's III., im Bauernkriege 1525 zerstört, von den Grafen von Hohenlohe dann eingezogen, in Folge des Restitutionsedictes vom J. 1629 durch den Abt von Kloster Zell, lem es untergeben war, wieder hergestellt, jedoch durch den westphälischen Frieden den. Hohenlohern wieder zugesprochen.

Erhalten haben sich noch aus dem 12. Jahrhundert sechs Urkunden im fürstlichen Archive zu Oebringen, aus dem 13.: 25 zu Oehringen, eine in Stuttgart (päbstliche Bulle), aus dem 14.: 75 in Oehringen, drei in Stuttgart und drei in Würzburg, aus dem 15.: 30 in Oehringen, zwei in Würzburg, wo sich noch eine aus dem 16. Jahrhundert, dann die Akten der Wiederherstellung aus dem J. 1630-43 (No. 215) befinden.

Viele Urkunden über Scheftersheim und die übrigen Hohenlohischen Klöster sind bei Hanselmann Hohenloh. Landeshoheit, und bei Wibel, Hohenloh. Kirchengeschichte, abgedruckt.

Copialbücher existiren nicht mehr.

Schlïchtern oder Solitaria,

in der obern Grafschaft Hanau, im späteren Kurfürstenthum Hessen gelegen, Benedictiner-Abtei, vor 817 gegründet und 1543 sükularisirt. 
Im Würzburger Archiv sind noch vorhanden 27 Originalurkunden aus dem 14. und 15. Jahrhundert und eine vom J. 1648; dann mehrere Copien.

Vergl. Geschichte der Abtei von S. E. Bernstein in der Zeitschrift Buchonia von J. Schneider. III. Band, 1. Heft, (1830) S. 164 u. ff.

\section{Sehmalkalden.}

1. Ein Aug u stiner-Eremiten-Kloster, dessen Gründung einem Dynasten von Frankenberg zugeschrieben wird und dessen Schirmvogtei die Grafen von Henneberg besassen. Die Zeit der Errichtung unbekannt, es bestand aber schon 1205, wurde 1525 im Bauernkriege ausgeraubt und 1548 von den geneinschaftlichen Landesherrn von Hessen und Henneberg sükularisirt.

Im k. Archiv ist kein Dokument über jenes Kloster vorhanden.

2. Ein Collegiatstift, gegründet am 1. Februar 1319 durch den Grafen Berthold VII. von Henneberg für zwölf Canoniker mit einem Dekan als Vorsteher und, nachdem die Landgrafen von Hessen durch den Spruch eines Austrägalgerichts 1498 von der Schirmvogtei ausgeschlossen waren, durch den Grafen Georg Ernst von Henneberg 1545 aufgehoben.

Im k. Archive hat sich nur eine Urkunde von J. 1389 erhalten. Mebrere Stiftsurkunden sind abgedruckt in: Wein $r$ ichs, Henneberg. Kirchenstaat S. 74 u. ff. Gfr. Ussermann p. 264-66.

Eine Arbeit nach den Quellen über beide Anstalten ist nicht vorhanden.

\section{Sohönan,}

an der Saale, unweit von Gemünden, Cisterzienser-Frauenkloster, in J. 1189 durch Friedrich von Hesler gegründet und nach dell Stürmen in der ersten Hälfte des 16. Jahrhunderts endlich 1564 aufgelöst. Kirche und das zerstörte Kloster wurden 1699 den Franziskaner-Conventualen überlassen, welche beide wiederherstellten und noch besitzen.

Eine Reihe gut orhaltener Urkunden ist noch vorhanden, 154 an der Zahl, ausser der Copie einer deutschen Uebersetzung des Stiftungsbriefes vier aus dem 12., 23 aus dem 13., 97 aus dem 14. Jahrhundert, die übrigen 30 aus der folgenden Zeit bis 1504, in welchem Aebtissin und Priorin ihr Kloster sammt Rechten und Gütern 'gegen ein Leibgeding übergeben, welches ihnen im Klnster' 
Paradies zu Heidingsfeld angewiesen wurde. Sie erhielten ihr Kloster aber noch einmal zurück, wie aus einem Zins- und Gefällsbuch (No. 216) erhellt, das auf Befehl der Aebtissin Cecilia von Königsfeld durcli Johann Greff Capellan im J. 1518 geschrieben wurde.

Ein zweites Zinsbuch (No. 217) liess Bischof Julius durch Hans Kind mit grosser Genauigkeit im J. 1586 anfertigen.

Mehrere Urkunden des Klosters sind gedruckt bei Gud en us, cod. diplom. T. V, p. 352 u. ff. und neun in Stumpf's Denkwiirdigkeiten (1804) Heft III, S. 78-94. Auf ihnen beruht die Geschichte des Klosters von F. N. Wolf im Archive des historischen Vereins Bd. IV, Heft 3, S. 54-71.

\section{Schronoln,}

Benedictiner-Priorat, am Main; unweit Gemünden, im J. 1093 durch Wilhelm, Abt von Hirschau, gegründet, durch den Bauernkrieg 1525 zerstört und als Kloster nicht wieder hergestellt.

Vorhanden nur noch drei Urkunden aus dem 15. Jabrhundert und eine aus dem 17. Gedruckt sind mehrere bei Gudenus 1. c. T. $\nabla$, p. 344 ff. Ofr. Us sermann p. 439.

\section{Sohonthal, Speciosa Vallis,}

Cisterzienser-Abtei, an der Jagst, jetzt zum k. württemberg. Oberamt Künzelsau gehörig, im J. 1157 von Wolfram von Bebenburg gegründet und 1802 von Württemberg aufgehoben und in ein protestantisches Seminar verwandelt.

Erhalten haben sich an .Original-Urkunden aus dem 12. Jahrhundert eine in Archive zu Würzburg (1171), aus dem 13.: $102 \mathrm{in}$ Staatsarchive zu Stuttgart und zwei in Würzburg, aus dem 14.: 320 in Stuttgart und vier in Würzburg, aus dem 15.: 339 in Stuttgart und eine in Würzburg, wo sich auch noch acht aus der späteren Zeit bis 1738 vorfinden.

Im Stuttgarter Staatsarchive sind dann ferner vorhanden: Verzeichnisse der Aebte und Conventualen, Annalen des Klosters, eine Chronik desselben mit Notizen vom 12. Jahrhundert an, drei Lagerbücher aus dem Ende des 15. Jahrhunderts und zwölf zum Theil aus mehreren Bänden bestehende Diplomatarien, welche ebenfalls Urkunden vom 12. Jahrhundert an enthalten. 
Hülfsmittel zur Geschichte: K r emer Barth., Chronicon Schoenthalense, Handschrift der k. öffentlichen Bibliothek in Stuttgart, Histor. fol. No. 422. - S c hö n h u th Otm., Chronik des Klosters Schönthal. Mergentheim 1850. 12. Hierin ist die Zunahme der Besitzungen anschaulich beschrieben. Einige Urkunden liess der Verfasser abdrucken in der Zeitschrift des histor. Vereins für das württemberg. Franken. III., 1 (1853), S. 81-85.

Schottenkloster zu Würzburg,

ad S. Jacobum, Benedictiner-Ordens, vom B. Embricho im J. 1138 errichtet; seine berühmtesten Aebte sind der hl. Makarius 1139-53 und Johann von Trittenhein 1506-1516; aufgelöset im J. 1802; das Kloster ist zum Militär-Lazareth, die Kirche, in Basilikenform, zu einem Drittel zum Gottesdienst und zu zwei Dritteln zu einer Wagenremise eingerichtet.

Vorhanden sind 138 gut erhaltene Urkundeu, wovon 25 dem 12 , die älteste ist der bestrittene Fundationsbrief rom J. 1140 durch Bischof Embricho, 35 dem 13., 28 dem 14., 12 dem 15. und 38 der späteren Zeit angehören.

Ein Copeibuch, unter der Regierung des Bischofs Julius 1587 angelegt, umfasst die collationirten Urkunden von 1140 an und fortgesetzt bis zur letzten, im J. 1798 errichteten, worin die Gattin meines Lehrers, des Professors Bodde in Münster, für Lesung einer ewigen Messe dem Kloster noch eine Summe von $8000 \mathrm{fl}$. übergibt (No. 195).

Von den drei Gült- und Zinsbüchern aus den J. 1482, 1479

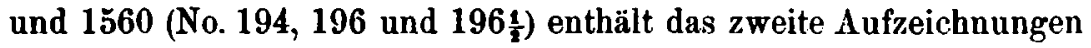
von der Hand des Trithemius.

Die übrigen Quellen gibt auf erster Seite die sehr gut geschriebene Geschichte des Schottenklosters von Dr. Mich. Wieland im 16. Bande des Archivs des histor. Vereins 1864.

\section{Sehwarzach,}

Benedictiner-Abtei, früher Frauenkloster mit Aebtissinnen aus der karolingischen Familie, im achten Jahrhundert gegründet, im Bauernkriege 1525 durch Brand zerstört, wobei das ganze Klosterarchiv vernichtet wurde, und 1802 aufgehoben.

Die schöne Kirche, die Zierde der Gegend, wurde in letzterer Zeit abgebrochen, das Kloster zu einer Fabrik eingerichtet. 
An Quellenmaterial ist wenig vorhanden; im Ganzen sind noch 33 Urkunden übrig, davon fünf aus dem 15. Jahrhundert, die älteste rom J. 1401, worin das Kloster um Schutz bittet gegen die Angriffe Krafts von Bieberehren; die jüngste vom 18. September 1805 ist der Verkaufbrief über sämmtliche Klostergüter an den jüdischen Handelsmann Jakob Hirsch.

Die im J. 1692 noch vorhandenen Erkunden wurden durch den öffentlichen Notar J. M. Ellgasser in ein Liber copiarum (No. 218) zusammengeschrieben; es sind einige mehr als wir jetzt haben.

Ueber den Catalogiss defunctorum conventualium mon. nostri Schw. aliorumque, qui vel confraternitate vel munificentia sua nobis se conmendatos reddiderunt. Philippus Eberdus Röttingensis scripsit hunc librum anno MVCXXVI - vergleiche den Abschnitt: Nekrologien.

Auch ein Protokollbuch (No. 2192) wurde unter dem Abte Georg nach der genannten Katastrophe seit 1530 angelegt und bis zur Mitte des vorigen Jahrhunderts fortgeführt.

Der historische Verein besitzt noch ein compendium historiae monasterii Schwarzach (M. S. f. *2) und historische Gedichte des Priors Burcard Bausch um 1700 (M. S. fol. 46 und 250), beide ohne vielen Werth.

Ueber die Geschichte des Klosters und die Aebte schrieben: Conr. Dinner, Catalogus et descriptio abbatum monasterii divae Felicitatis vulgo Munsterschwarzach. Wirtzburgi 1586. In heroischen Versen. - Vitae et res praeclare gestae abbatum in MünsterSchwarzach. Wirceburgi 1743. 4. - Vergl. Us sermann p. 288.

Das Chronicon Schwarzacense, welches Ludewig im 2. Bande der SS. rerum episcopatus bambergensis (17.18) pag. 1-48 mittheilte, reicht bis 1550 und beruht in seinen ersten Theilen auf älteren Aufzeichnungen.

\section{Schwoinfurt.}

In dieser Reichsstadt finden wir zuerst ein Benedictinerkloster, dunkeln Ursprungs, aber vor 1200 bestehend, das in geistlicher Beziehung unter Würzburg, in weltlicher unter den Bischöfen von Eichstädt stand, von denen es Reinboto dem deutschen Orden 1283 übergab. Die um diese Zeit hier bestandene Commende wurde schon nach fünfzehn Jahren mit der zu Münnerstadt verbunden. 
Ein zweites, den Carmelitenorden angehöriges Kloster, in J. 1366 gegründet, wurde nach zwei Jahrhunderten in markgräflichen Kriege zerstört.

Ueber das erste Kloster haben wir keine Dokumente, über das zweite einige wenige, oben unter Carmeliter aufgeführte, Urkunden und Akten.

$$
\text { Seligensthal, Vallis Beatorum, }
$$

Cisterzienser-Frauenabtei, im Odenwalde, nach Fries im J. 1239 von Conrad Grafen von Düren gestiftet, im 14. Jahrhundert an Mainz gekommen, welches nach dem Erlöschen desselben die Einkünfte dem Jesuitencollegium 1568 zuwandte. Vorhanden sind noch 257 Urkunden, davon 71 dem 13., 70 dem 14., 90 dem 15. und die übrigen bis 1576 dem folgenden Jahrhundert angehören.

Sinnershausen, oder Rosenthal, Vallis Rosarum,

Wilhelmiterkloster, bei Hümpfershausen im Herzogthum SachsenMeiningen, von einem Ritter von Katza vor 1290 gegründet, im Bauernkriege zerstört und darauf von den Grafen von Henneberg eingezogen und verkauft.

Keine Urkunde mehr vorhanden. Cfr. Br ü ckner, eine (vortreffliche) Monographie in einem Schulprogramme von Meiningen vom J. 1861.

$$
\text { Sonnenfeld, Campus Solis, }
$$

eine Cisterzienser-Frauenabtei, im Herzogthum Sachsen -Coburg, im J. 1260 durch Heinrich von Sonuenberg und seine Gemahlin Kunegunde gegründet und in J. 1528 von den Herzogen von Sachsen säkularisirt.

Uebrig ist noch eine Urkunde. Das Diplomatar des Klosters in dritten Bande von Schöttgen und Kreysig, diplomatar. Cfr. Uss erman n p. 476 . -

\section{St. Stephan zu Würzburg,}

berühmte Benedictiner-Abtei, errichtet als solche von Bischof Adalbero im J. 1057, säkularisirt 1802 . Die Klosterkirche ist jetzt die protestantische Pfar'kirche, das Kloster Sitz der kgl. Kreisregierung, im Keller die Champagnerfabrik von J. M. Vornberger.

Das Klosterarchiv befand sich einst in vorzüglich geordnetem Zustande, wie das noch erhaltene Repertorium desselben (No. 223) 
aus dem J. 1767 beweiset, und schannat, der dasselbe benutzen konnte, hatte Recht, wenn er $\mathbf{1 7 2 3}$ das archivum chartis et diplomatibus eleganter conservatis instructissinum nannte. Die Urkunden sind noch jetzt durchschnittlich gut erhalten.

Die Quellen der Geschichte der Abtei sind:

1. Die Urkunden, wovon sich an Originalen $790 \mathrm{im} \mathrm{k}$. Archive befinden. Davon gehören zwei dem 11., 28 dem 12. (eine fehlt in Langs Regesten), 63 dem 13., 120 den 14., 218 dem 15. Jahrhundert und 359 der folgenden Zeit an. Die Reihe beginnt mit den Stiftungsbriefe vom 7. März 1057, wodurch Bischof Adalbero statt der seit ungefähr 1013 hier lebenden Canoniker nun Benedictiner hieher versetzt, und schliesst mit dem Jahr 1798.

In der Mitte liegen die Reformationen des Klosters durch die Bischöfe Otto und Albert 1344 und 1348 und die Besetzung desselben durch die Schweden von 1631-34, die sich besonders mit den Einkünften befassten.

2. Zwei sogenannte Rotuli donationum, die sich beide erhalten haben, aus dem Anfange des 12. Jahrhunderts. Sie sind ans mehreren Streifen Pergament zusammengenäht, um ein rundes Stäbchen gerollt und dienten wie später die Copialbücher dazu, die Angehörigen des Klosters mit den Besitztiteln ùnd den Wohlthätern bekannt zu machen, ohne die kostbaren Originalurkunden abzunützen. (Vergl. auch Du Cange, glossar. s. h. v. V, 809). Der erste Rotulus, $71 / 2$ Zoll breit und 18 Fuss lang, auf beiden Seiten beschrieben, umfasst 72, der zweite 86 Abschriften von Schenkungsbriefen. Beide Rotuli hat Schannat in seinen Vindemiis literariis (Fuldae et Lipsiae 1723) Coll. I, pag. 53-91. als Traditiones veteres coenobii S. Stephani Herbipoli in der Weise veröffentlicht, dass er die Urkunden leider in chronologischer Ordnung, mit Hinzufügung einzelner bischöflicher Bestätigungsbriefe aus den Originalen, von 1057-1168 zusammenstellte und ihnen die ohne Zeitangabe folgen liess. Aber der Abdruck ist nicht ganz genau und nicht vollständig, denn statt der 158 Urkunden, welche die Rotuli haben, gibt er nur 93, so dass eine neue Benutzung jener nicht umgangen werden kann.

3. Copialbücher: Es sind davon drei Bände (No. 220-22) vorhanden, wovon der erste, aus dem Ende des 15. oder Anfang des 16. Jahrhunderts, im Anfang auch die von Bischof Conrad von Thüngen 1525 gegebene neue Ordnung des Stadtgerichts zu Würzburg 
hat, der dritte die Einträge bis ungefähr 1720 enthält. Den besten Index dazu hat das oben genannte Repertorium archivi.

4. Ein Necrologium, das aber nur für das Kloster einige Bedeutung hat, aus dem 17. Jahrhundert, herausgegeben von Wegele in den fränkischen Nekrologien S. 45-70. Vergl. dazu die Nekrologien.

5. Ein Diarium rerum gestarum in monasterio St. Stephani a 7. Julii 1713 coeptum a F. Alberico Ebenhöch abbate. Es ist fortgeführt bis zum J. 1738 und enthält auch eine Series sive Catalogus fratrum hujus Monasterii ab anno 1619, fortgesetzt bis zur Aufhebung des Klosters (M. S. 31).

Derselbe Abt verfasste auch eine kurze Geschichte seiner Vorgänger, einen Catalogus Abbatum, wie schon früher um das J. 1560 Abt Jodocus einen solchen entworfen hatte. Das grösste Verdienst desselben um die Geschichte seines Klosters besteht darin, dass er ein Mitglied seines Convents, dessen Namen sich nicht erbalten hat, veranlasste, über die Vorzeit seiner Abtei und ihrer Vorstände eine Arbeit zu verfassen, welche, nach den erhaltenen Bruchstücken zu urtheilen, als für ihre Zeit ganz vortrefflich zu bezeichnen ist. Derselbe theilte sein für den Druck bestimmtes Werk in drei Theile, wovon der erste einleitende die Gründung und Beschreibung des Klosters, der zweite die Lebensbeschreibung der Aebte, der dritte die Urkunden des Klosterarchires enthielt. Erhalten hat sich daron nur von dem zweiten Theile die nach den Urkunden bearbeitete Geschichte der ersten fünf Aebte von 1057-1166 und die der Aebte von 1627-1731; nit dem 23. Juni dieses Jahres bricht seine Arbeit ab, an deren Fortführung ihn wohl der Tod hinderte. Diesc Fragmente finden sich in den Sammlungen des historischen Vereins (M. s. fol. 790); das vollständige Werk diente der letzten Arbeit des fleissigen Stiftschronisten Ignaz Gropp, welcher ebenfalls noch unter der Regierung des genannten thätigen Vorstandes seine erste historische Schrift (Vita s. Bilihildis) herausgab, als Grundlage. Gropp hatte vor, eine Franconia Benedictina zu verfassen, eine Geschichte der Benedictinerklöster in Franken, brachte aber nur, bei Gelegenheit der siebenhundertjährigen Säkularfeier seiner Abtei 1757, ein Jahr vor seinem Tode (er starb am 19. November 1758), in Folge von Schwierigkeiten, über die er klagt, ein kleines Werk zu Stande, dem er den Titel gab: Ecclesia S. Stephani cum monasterio $\mathrm{S}$. Benedicti in reverendissimis suis abbatibus cum rebus per elapsa 
septem saecula cirea se gestis, historioca methodu repraesentata. Es betindet sich im historischen Vereine, in der Originalhandschrift (I. s p. 136) und in gefälliger Abschrift mit Hinzufïgung der Jahre bis 1762 (M. S. octav. 6).

Nach diesem verfasste nun Ussermann in seinem Episc. Wirceb. pag. 268-79 seine kurze Geschichte und Series abbatum, das einzige, was wir bis jetzt über $\$$. Stephan besitzen.

Dic Urkunden dieses Klosters sind wegen der vielen Besitzungen desselben in Würzburg für die städtische Lokalgeschichte von grossem Interesse und noch gar nicht benutzt.

Sulz,

Prämonstratenser-Nonnenkloster an der Quelle der Sulz, k. Bezirksants Rothenburg a/T., in Mittelfranken, um 1130 gegründet, im Bauernkriege 1525 zerstört und 1531 von dem Markgrafen Georg dem Frommen eingezogen.

Im k. Archive zu Nürnberg sind von Sulz 269 Urkunden verwahrt, davon neun aus dem 13., 82 aus dem 14., 133 aus dem 15. und 45 aus dem 16. Jahrhundert. Im $k$. Archive za Würzburg ist keine Urkunde mehr übrig.

\section{Theres,}

Benedictiner-Abtei, am Main zwischen Schweinfurt und Hassfurt, in J. 1043 durch Suidger, den zweiten Bamberger Bischof und späteren Papst Clemens II., gegründet, in den Jahren 1466, 1525 und 1553 vielfach geschädigt und durch die churfürstlich bayerische Regierung 1802 aufgehoben. Das Kloster ist jetzt Besitzthum des Herrn von Swayne.

An Originalurkunden sind noch 42 vorhanden, eine aus dem eilften Jahrhundert: die Bestätigungsurkunde Pabsts Clemens II. vom J. 1047, drei aus dem 12., zwei aus dem 13., vier aus dem 14., acht aus den 15. und 24 aus der folgenden Zeit; die letzte ist der Verkaufsbrief der schönen Abtei und ihrer bald darauf niedergerissenen Kirche an den coburgischen Minister Theodor von Kretschmann.

Kein Kloster in Franken hat mehr Copialbücher als Theres, das, in geistlichen Dingen unter Würzburg, in weltlichen unter Bamberg stehend, allen Grund hatte, auf seine Privilegien zu halten. Beim Herannahen der Raubschaaren des Markgrafen Albrecht von 
Brandenburg schickte der Abt seine Dokumente der Sicherheit wegen nach Würzburg. Bischof Friedrich behielt sie aber und schickte dem Kloster dafür Copien, welche in dem Copialbuche des Abtes Johannes Schüssler (1545-74) abgeschrieben sind (No. 224). Vollständiger ist ein zweites Copeibuch aus dem J. 1593, welches 104 Urkunden enthält (No. 226). Ein drittes (No. 225) aus dem J. 1595 enthält $\Delta$ bschriften von Urkunden, die ebenfalls in Würzburg verwahrt sind. Das vierte ist ein Copeibuch, angelegt im J. 1602 mit vorausgehendem „Protokoll über alle und jede des Kloster Theres briefliche Urkunden und Dokumente" (No. 227). -- Ein Copeibuch aller in den Jahren 1642-48 ein- und ausgelaufenen Schreiben enthält No. 228 und No. 229 die Recesse von den J. 1659-1745. Die dem Abte von Theres von der bischöflichen Kanzlei in Würzburg 1561 zugesendeten 71 Copien nebst einigen zugeschriebenen sind zusammengebunden in No. 230. Eine andere durch den kaiserlichen Notar Jol. Acker vidimirte Copiensammlung derselben Urkunden aus dem J. 1561 ist No. 232, in grün Leder gebunden und sehr deutlich geschrieben. In No. 234 sind sehr verschiedene Papiere aus dem Anfange des 17. Jahrhunderts, die Theres näher oder ferner berühren, zusammengebunden. Ein im 15. Jahrhundert geschriebenes Büchlein (No. 236) enthält eine Zusammenstellung mehrerer Gerechtsame des Klosters in verschiedenen Orfen, ein anderes ähnliches Buch (No. 233), ist aus dem vorigen Jahrhundert. Auch der historische Verein besitzt eine Sammlung von Copien, Akten und Klostergeschichten.

Eine historische Beschreibung der Abtei von dem Prior Gregor Fuchs (No. 231) geht bis zum J. 1711 und ist ron da bis zum J. 1766 fortgesetzt worden, zuletzt von dem. letzten Abte Benedict Mahlmeister, welchem auch Ussermann die Notizen über die Reihenfolge der Aebte in seinem Fpisc. wirceb. pag. 304-310 verdankt.

\section{Triefenstein,}

(Stillans Petra) eine Probstei von Regularcanonikern, am Main, k. Bezirksamts Marktheidenfeld, im J. 1088 von Gerung, Canoniker von Neumünster, gestiftet und nach der Säkularisation 1802 durch den Reichsdeputationshauptschluss der älteren Linie des Hauses Löwenstein-Wertheim als Entschädigung zugewiesen.

Es sind noch 13 Urkunden im $k$. Archiv, davon zwei aus dem 14., fünf aus dem 15. Jahrhundert, die andern sechs aus 
späterer Zeit; ferner ein von einem kaiserlichen Notar 1692 schlecht geschriebener liber copiarum (No. 237), der nur eine kleine Anzahl Urkunden enthält, und ein Fundationsbuch oder Mortilegium (No. 237.), worin die Pröbste, Canoniker und Wohlthäter des Klosters und ihre Todesjahre, aber nicht in Form der Calendarien, verzeichnet sind.

Einige Urkunden liess $\mathrm{MI}$ o n e, Zeitschrift 4, 406 u. ff. abdrucken aus dem Wertheimer Archiv, worin sich auch eine ausführliche Klosterchronik befindet (eine Abschrift davon im historischen Vereine zu Würzburg), wonach Mone a. a. St. die von Ussermann gegebene Reihe der Pröbste berichtigte.

\section{Trostadt,}

Prämonstratenser Frauenkloster, im Werragrund, im Herżogthum Sachsen-Meiningen, gegründet im J. 1176 durch Bertha, Wittwe des Grafen Berthold I. von Henneberg, im Bauernkrieg 1525 zerstört und darauf eingezogen.

Keine Urkunde ist im Würzburger Archive mehr vorhanden. Cfr. U s s e r m a n n p. 490. Br ü ckner, Landeskunde S. 261,

\section{Ttiokelhausen,}

in der Nähe von Ochsenfurt, um das J. 1138 für Prämonstratenser gestiftet, welche unter der Aufsicht von Oberzell hier wohnten, bis 1305 die Prämonstratenserinnen von Michelfeld bei Kitzingen hier angesiedelt wurden, aber den Platz 1351 an die Karthäuser überlassen mussten, welche nun in diesem von ihnen Cella Salutis genannten Kloster bis 1802 wohnten. Jetzt ist es Privateigenthum. Die Zahl der erhaltenen Urkunden ist 309, davon drei aus dem 12., die älteste von Bischof Gebhard um 1153-57, eine aus dem 13., 50 aus dem 14., 143 aus dem 15. Jahrhundert und 112 aus späterer Zeit.

Die Karthäuser haben für die Erhaltung ihrer Dokumente gut gesorgt. In dem 17. Jahrhundert haben sie zwei grosse Sammlungen von Copien ihrer Briefschaften und zwar nach Orten angelegt; in die erste, die sie Saalbuch nannten, zuerst die Einkünfte und dann die Erwerbsdokumente eingetragen (No. 240-42), in die zweite (No. 242 ${ }^{a-c}$ ) letztere allein; sie sind in den Jahren 1670-80 geschrieben. Sie sorgten auch für Erhaltung des Andenkens an ihre früheren Brüder; die historia Carthusiae Tückelhausen (No. 2421/2) 
enthält ein von mehreren Händen bis zu Ende des 18. Jahrhunderts fortgeführtes Namensregister mit Angabe des Todestages. Aehnlich ist die Handschrift des historischen Vereins: Origo et succesus monasterii Cellae Salutis in Tuckelhausen (M. S. f. 41); derselbe besitzt auch Klosterrechnungen aus dem 17. und 18. Jahrhundert, ein Notizbuch mehrerer Priore zu Tückelhausen von 1640—90 (M. S. f.* 162 und 40), welche Herrn Professor Denzing er den Stoff z.u dem Aufsatze lieferten: Die Bauern, Schweden und Franzosen im Carthäuserkloster Tückelhausen (im 13. Bande des Archivs des historischen Vereines, Heft 1. (1854) S. 276-99.

\section{S. Ulriehskloster zu Würzburg,}

Benedictiner-Frauenkloster, in dor Mitte des 13. Jahrhunderts gestiftet, im 16. aufgelöset; die Einkünfte desselben von B. Julius seiner neugegründeten Universität zugewandt.

Es sind noch 21 Urkunden davon übrig, drei aus dem 13., die älteste vom Jahre 1256, fünf aus dem 14., acht aus den 15. und fünf aus dem 16. Jahrhundert; die letzte von 1570 ist ein Verzeichniss der Einkünfte des Klosters.

\section{Ursulinorkloster zu Würzburg,}

als Filiale des Kitzinger Klosters dieses Ordens 1710 gegründet, durch die kurfürstlichó bayerische Regierung 1804 aufgehoben, durch den Grossherzog Ferdinand 1808 wieder hergestellt und für Unterricht und Erziehung fortwährend thätig.

Die 26 vorhandenen Urkunden gehen von 1711 bis 1796 .

\section{Vellsdorf,}

an der Werra im Coburgischen, Benedictinerinnen-Abtei, um 1180 gegründet, 1446 in eine Benedictiner-Abtei verwandelt, im Bauernkriege 1525 zerstört und dann aufgelöset.

Es sind im k. Archive noch drei Urkunden vorhanden, die Stiftungsurkunde von 1189 und zwei aus dem 14. Jahrhundert. Vicle sind gedruckt in $\mathrm{Sch} \ddot{\mathrm{ttg}} \mathrm{en}$, diplomat. medii aevi II, p. 621 .

\section{Vessera,}

Prämonstratenser-Mönchskloster, am Zusammenfluss der Werra und Schleussa, im Hennebergischen, im J. 1131 durch Gotebold Grafen von Henneberg gegründet und um 1560 durch Johann Friedrich 
Kurfüsten von Sichsen als Erben des (irafen Wilhelm ron Henneberg säkularisirt.

Keine Urkunde ist im würzburger Arehive melır iibrig. Clr. Ussermann, Ep. Wirceb. p. 486. - Schultes, Neue diplomat. Beiträge I, 197.

\section{Vogelsburg.}

Siehe Carmelitenklöster.

\section{Wasangen,}

ein Wilhelmiterkloster, beim Einfluss der Katze in die Werra im Herzogthum Sachsen-Meiningen, im J. 1299 von einem Herrn von der Kehr gegrïndet, im Bauernkriege 1525 zerstört und nach der in den Hennebergischen Landen eingeführten Reformation in ein Domainengut verwandelt.

Urkunden keine im würzburger Archiv vorhanden.

\section{Weohterswinkel,}

Benedictiner- später Cisterzienser-Frauenabtei, gegründet um die Witte des 12. Jahrhunderts; nach Zerstörung der Gebäude im Bauernund markgräflichen Kriege wurden vom Bischof Julius, nachdem seine Bemühungen, das Kloster wieder aufzurichten, gescheitert waren, die Einkünfte desselben Cultuszwecken zugewiesen.

Der Vorrath an Originalurkunden und einigen Copien beläuft sich auf 62, darunter 14 aus dem 12. Jahrhundert, die älteste vom J. 1143, fünf aus dem 13., drei ans dem 14., sechs aus dem 15. und die andern 34 aus neuerer Zeit. Die letzte ist diessmal nicht der Verkaufsbrief der Klostergüter, sondern enthält die Bestimmung des Grossherzogs Ferdinand von Würzburg vom 11. März 1809, wornach die Einkünfte des Klosters zur katholischen Pfarreien- und Schulenstiftung verwendet werden sollen.

Erhalten ist uns ferner ein vortreffliches Diplomatarium aus der Mitte des 14. Jahrhunderts (No. 238); soweit reichen auch die 182 Urkunden enthaltenden, von einer Hand geschriebenen, Einträge von Blatt $1-59$, denen andere von verschiedenen Händen bis Blatt 78 folgen; es ist auf Pergament deutlich und kräftig geschrieben und zwar auf jeder Seite mit 34 durchlaufenden Linien. Ausser dem Register ist ein Calender aus derselben Zeit, dem das letzte Blatt fehlt und der ausser der Angabe der Heiligen keine Einträge hat, vorgebunden. Auffallend ist, dass die Bestätigungs- 
urkunde Bischofs Hermann über die von dem Grafen Otto ron Hiltenburg im Kloster Wechterswinkel getroffene Anordnung rom J. 1231 (s. Jaeger, Gesch. Frankenlands III. p. 360) hier fehlt, wie in den Mon. boicis. Eine nicht immer correcte Abschrift des Copeibuchs, copia collationata libri copiarum, cujus originale repositum est in Archivo Reverendissimi ac illustrissimi Capituli Herbipolensis, aus dem J. 1785 ist No. $238^{\mathrm{a}}$; No. $238^{\mathrm{b}}$ enthält ein Urbarbuch des Klosters aus den Jahren 1590-1614 nach den verschiedenen Orten, woraus dasselbe Einkünfte bezog.

Eine Geschichte des Klosters mit den Urkunden-Regesten von Dr. Himmelstein befindet sich im Bd. XV des Archivs des historischen Vereins (1860), Heft 1, S. 115-176.

\section{Werthoim}

hatte eine durch den Grafen Johann II. 1419 mit einem Pfarrer und zehn Vikarien fundirte Parochialkirche, welche unter der Regierung des Grafen Johann III. durch eine besondere Bulle des Papstes Sixtus IV. 1481 zu einem Collegiatstift erhoben wurde, an welches ein Dechant mit dreizehn Canonikern zu stehen kam. Es bestand bis 1549, wo es durch den protestantisch gewordenen Grafen Michael III. aufgehoben wurde.

Die betreffenden Urkunden befinden sich im fürstlich Löwensteinischen Archive zu Wertheim und sind schon verwerthet in der trefflichen Geschichte der Grafen von Werthein von den ältesten Zeiten bis zu ihrem Erlöschen im Mannesstamme in J. 1556, aus den urkundlichen Quellen bearbeitet von J. A s chbach, Frankfurt, zwei Theile, 1843. Die genannte Bulle in II. Bande, der das wertheimische Urkundenbuch enthält, S. 292.

\section{Windsheim.}

Augustiner Eremitenkloster, Stadt in Mittelfranken, im J. 1290 gestiftet und 1525 aufgehoben.

Urkunden nicht vorhanden.

Wtirzburg.

Siehe Carmelitenklöster.

$"$ Augustiner.

" Stift Haug.

$" \quad$ "Neumünster. 


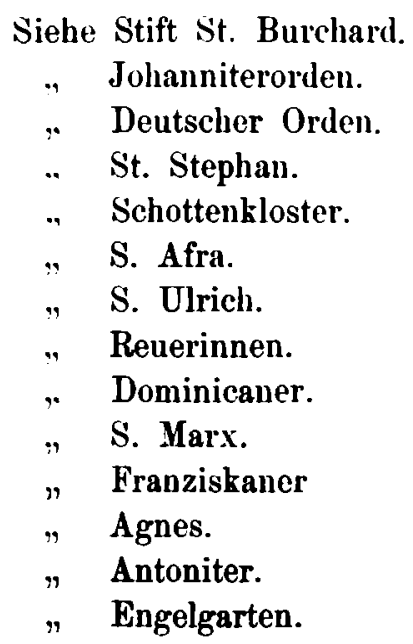

\section{Zell,}

1. Oberzell, Cella Dei superior, am Main bei Würzburg, Prämonstratenser-Abtei im J. 1128 gegründet und bestanden bis 1802. In dem grossen Klostergebäude ist jetzt die berülumte Schnellpressenfabrik von König und Bauer.

Uebrig sind noch 204 Urkunden, davon 18 aus dem 12., die älteste ist die Bestätigungsurkunde des Bischofs Embricho vom J. 1128, acht aus dem 13., 31 aus dem 14., 66 aus dem 15. Jahrhundert und 81 aus der folgenden Zeit bis 1805, wo die Verkaufsurkunde der Klostergüter den Schluss macht.

Auch sind Copialbücher, im 17. Jahrhundert geschrieben und nach den Pfarreien, Ortschaften und Besitzungen geordnet, in drei Bänden erhalten (No. $262^{\text {a.b.c. c.). }}$.

Ueber den catalogus defunctorum, in historischen Vereine, vergleiche die Nekrologien.

Eine Geschichte des Klosters von Pfarrer Kestler befindet sich im 14. Bande des Archivs des historischen Vereins H. 1, S.37-128.

2. Unterzell, Cella Dei inferior, durch das Dorf Zell von dem obern Kloster gesehieden, Prämonstratenser Frauen-Abtei, ebenfalls um 1130 gegründet und bis 1802 bestanden. Die Kirche und die Gebäude theils zerstört, theils zu kleinen Wohnungen eingerichtet.

An Urkunden sind 59 vorhanden, eine aus dem 13., zwei aus dem 14., 11 aus dem 15. Jahrhundert und 45 aus der folgenden 
Zeit. Den Schluss macht wieder der Verkaufsbrief der Klostergüter aus dem J. 1805.

Fine Geschichte dieses Klosters von Pfarrer Kestler im X. Bande des Archivs des historischen Vereins Heft 1, S. 87-104.

Zella unter Fis c h berg.

Benedictiner-Nonnenkloster, am Nordostsaum der Rhön, nun im Grossherzogthum Sachsen-Weimar, um 1136 durch den h. Otto in eine Probstei umgewandelt, die bis 1801 bestand.

Vorhanden sind im Würzburger Archiv nur noch drei Verträge der Bischöfe von Würzburg mit den Aebten von Fulda über gegenseitige Recesse wegen der Probstei aus dem 16. und 17. Jahrhundert. Eine gute Monographie von W. Rein im XV. Bande des Archivs des historischen Vereins (1860). Heft 2 und 3, S. 332-356.

(Schluss folgt.) 